\title{
Radiation effects in glasses used for immobilization of high-level waste and plutonium disposition
}

\author{
William J. Weber \\ Pacific Northwest National Laboratory, P.O. Box 999, M.S. K2-44, \\ Richland, Washington 99352 \\ Rodney C. Ewing a) \\ Department of Earth and Planetary Sciences, University of New Mexico, \\ Albuquerque, New Mexico 87131 \\ C. Austen Angell \\ Department of Chemistry, Arizona State University, Tempe, Arizona 85287
}

George W. Arnold

Consultants International, 11729 S Highway 14, Tijeras, New Mexico 87059

Alastair N. Cormack

NYS College of Ceramics, Alfred University, Alfred, New York 14802

Jean Marc Delaye

DTA/SRMP, Centre d'Etudes de Saclay, 91191 Gif-sur-Yvette Cedex, France

David L. Griscom

Naval Research Laboratory, Washington DC 20375

Linn W. Hobbs

Department of Materials Science and Engineering, Massachusetts Institute of Technology, Cambridge, Massachusetts 02139

Alexandra Navrotsky ${ }^{\mathrm{b})}$

Geological and Geophysical Sciences \& Princeton Materials Institute, Princeton University,

Princeton, New Jersey 08544

David L. Price

Materials Science Division, Argonne National Laboratory, Argonne, Illinois 60439

A. Marshall Stoneham

Department of Physics and Astronomy, University College London,

London WC1E 6BT, United Kingdom

Michael C. Weinberg

Department of Material Science and Engineering, University of Arizona,

Tucson, Arizona 85721

(Received 28 October 1996; accepted 17 April 1997)

This paper is a comprehensive review of the state-of-knowledge in the field of radiation effects in glasses that are to be used for the immobilization of high-level nuclear waste and plutonium disposition. The current status and issues in the area of radiation damage processes, defect generation, microstructure development, theoretical methods and experimental methods are reviewed. Questions of fundamental and technological interest that offer opportunities for research are identified.

a) Present address: Nuclear Engineering and Radiological Sciences, University of Michigan, Ann Arbor, Michigan 48109-2104.
${ }^{b}$ Present address: Department of Chemical Engineering and Materials Science, University of California at Davis, Davis, California 95616. 


\section{TABLE OF CONTENTS}

\section{INTRODUCTION}

A. High-level nuclear waste and plutonium

B. Principles of radionuclide immobilization in glass

\section{PRINCIPLES OF RADIATION EFFECTS}

A. Radiation sources

B. Interaction of radiation with glass

1. Ionization and electronic excitation

2. Ballistic processes

3. Transmutations and gas production

C. Irradiation techniques

1. Actinide-incorporation

2. Actinides in natural glasses

3. Charged-particle irradiation

4. Gamma irradiation

5. Neutron irradiation

\section{STRUCTURE AND RADIATION EFFECTS} IN GLASSES

A. Structure of glasses

B. Silica glass

1. Macroscopic changes

2. Point defects

C. Alkali silicate glasses

1. Macroscopic changes

2. Point defects

D. Borosilicate glasses

1. Macroscopic changes

2. Point defects

E. Simulated waste glasses

1. Volume changes

2. Stored energy

3. Helium accumulation

4. Microstructural changes

5. Mechanical properties

6. Enhanced diffusion

7. Radionuclide release

IV. FUNDAMENTAL SCIENTIFIC ISSUES

A. Glass structure and energetics

B. Ionization versus ballistic effects

1. Electron- and X-irradiations

2. Ion-irradiations

C. Relaxation processes and diffusion

1. Relaxation processes

2. Diffusion

D. Temperature and dose rate effects

E. Radiation-induced transformations

1. Phase separation

2. Devitrification

3. Amorphization of crystalline phases

F. Volume changes

G. Gas accumulation and bubble or void formation

H. Chemical durability

I. Theory and computer simulations

V. RESEARCH FACILITIES

A. Actinide research facilities

B. Gamma irradiation facilities

C. Ion-beam irradiation facilities

D. Electron-beam irradiation facilities
VI. RESEARCH NEEDS 1973

A. Reference glass compositions 1973

B. Structural and thermodynamic properties 1973

C. Systematic irradiation studies 1973

D. Theory and computer simulations 1974

E. Facilities 1974

F. Attract talented scientists 1974

ACKNOWLEDGMENTS 1974

REFERENCES 1975

\section{INTRODUCTION}

Stabilization and immobilization of high-level tank waste, high-level sludge in fuel storage basins, and plutonium $(\mathrm{Pu})$ residues/scraps are some of the largest and most costly challenges facing the U.S. Department of Energy (DOE) in its effort to close the nuclear fuel cycle and cleanup the DOE weapons complex. ${ }^{1}$ In addition, the immobilization and disposal of surplus weapons-grade plutonium creates growing technological demands and raises political issues that are historically and technically tied to DOE's environmental management and restoration activities. ${ }^{2,3}$ In most cases, these high-level nuclear wastes (HLW) will be immobilized in glass waste forms prior to permanent disposal in a geologic repository. The immobilization and disposal of HLW and $\mathrm{Pu}$ in glass waste forms is a global issue, as other countries also address the issues of surplus weapons $\mathrm{Pu}$ and continue to produce HLW from the reprocessing of commercial nuclear fuels. A key challenge in the permanent disposal of HLW and $\mathrm{Pu}$ is the development of predictive models that are based on a sound scientific understanding of relevant phenomena, including the effects of radiation, thus allowing the assessment of long-term performance. The durability of HLW glasses has been studied in detail, ${ }^{4-6}$ but with limited consideration of the effects of radiation from the decay of the incorporated fission products and actinides. Such radiation effects could potentially impact the longterm performance and environmental risk of glasses for HLW and Pu immobilization and disposal. In general, there is insufficient scientific or engineering data in the current literature to fully assess the actual impact of radiation on glass waste form behavior.

In order to assess the current state of understanding, identify relevant scientific issues, and determine directions for future research in the area of radiation effects in glasses for the immobilization of high-level waste and plutonium, a panel was convened in Santa Fe, New Mexico, on February 25-29, 1996, under the auspices of the Department of Energy, Council on Materials Science. The primary objective of this twelve member panel, which was chaired by W.J. Weber and R.C. Ewing, was to identify the fundamental scientific issues that need to be addressed and techniques available in 
order to: (i) advance the understanding of radiation effects in complex glasses, (ii) perform accelerated irradiation studies and computer simulations to doses corresponding to $10^{4}$ to $10^{6}$ years of storage, and (iii) provide the sound scientific base needed to develop predictive strategies and models for the performance of nuclear waste glasses. This report summarizes the deliberations and conclusions of the panel.

The effect of radiation on HLW glass is of special importance because a major portion of the high-level defense waste in the U.S. is destined for incorporation into a borosilicate glass waste form. The glass waste form is the first barrier to the release and dispersion of radionuclides, and at the same time, the materials properties (e.g., leach rate, stored energy, and volume expansion) of glasses can be very sensitive to interactions with a radiation field. The recent proposal to incorporate excess weapons plutonium in glass ${ }^{2,3,7}$ has only increased the need to understand the effects of high-radiation doses on the performance of a broad range of nuclear waste glasses. The very high cost of vitrification facilities [up to 4 billion dollars for the Defense Waste Processing Facility (DWPF) at the Savannah River Site ${ }^{8}$ ], the long times required for construction of the facilities [13 years and 12 years for the construction of DWPF and the West Valley Demonstration Project (WVDP) in New York, respectively ${ }^{9}$, and the extremely long time periods $\left(10^{4}\right.$ to $10^{6}$ years $)$ required by disposal in a geologic repository, mandate a prudent need for a fundamental, scientific understanding of relevant phenomena, such as the effects of radiation on the nuclear waste glass. To begin, a brief review of the nature of the waste, characteristics of the waste form glass, and the scale of the problem are presented.

\section{A. High-level nuclear waste and plutonium}

The disposal of high-level radioactive waste from nuclear weapons production, naval propulsion programs, and the processing of commercial spent nuclear fuels in technically advanced countries is a growing global issue. In the United States, defense HLW was generated as a result of DOE reprocessing operations at the Hanford Site (Washington), the Savannah River Site (South Carolina), and the Idaho National Engineering Laboratory. The DOE also is responsible for the liquid waste produced in the 1960s at a demonstration plant in West Valley, New York, for the reprocessing of commercial spent nuclear fuel. Currently, about 100 million gallons of HLW under the stewardship of the U.S. DOE is stored in 243 underground tanks in Washington, South Carolina, Idaho, and New York. ${ }^{1}$ These wastes are the legacy of 50 years of research, production, and testing of nuclear weapons at a cost of over 300 billion dollars (in 1995 dollars). The cleanup of the weapons complex is in its early stages with an anticipated expenditure of hundreds of billions of dollars in an effort that will continue well into the 21 st century.

The HLW at the Savannah River and the West Valley Sites are destined for immobilization in a borosilicate glass. Specific glass compositions have been developed for $\mathrm{DWPF}^{10}$ and $\mathrm{WVDP}^{11}$; however, glass compositions for the Hanford tank waste have not yet been selected or developed. Vitrification plants have a long operating history in France and have been operated or are operating in England, Belgium, India, Japan, and Russia. Both the DWPF and WVDP started production of canisters filled with HLW glass (approximately $3 \mathrm{~m}$ high and 0.6 m diameter $^{10}$ ) in 1996 and are scheduled to produce 6000 canisters over 25 years $^{12}$ and 300 canisters over 2.5 years, ${ }^{11}$ respectively. At present, the majority of the high-level defense waste is stored in tanks at the Hanford and Savannah River sites in Washington and South Carolina, respectively. The volumes are substantial. At the Hanford site alone the inventory includes 11 million $\mathrm{m}^{3}$ of fluids and 6900 metric tons of nuclear materials, which includes 4100 metric tons of uranium and 15 metric tons of $\mathrm{Cs}$ and $\mathrm{Sr}$ in capsules. ${ }^{13}$ The total activity of the waste at the Hanford site is estimated to be 446 million curies. ${ }^{13}$ For all of the principal DOE sites (Hanford, Savannah River, Idaho Nuclear Engineering Laboratory, and the West Valley Demonstration Project), the combined total volume of high-level waste (through 1988) is $385,000 \mathrm{~m}^{3}$, and the total activity is $1,200,000,000$ curies. ${ }^{14}$ Although the defense high-level wastes account for $95 \%$ of the volume of the current total United States HLW inventory, they account for only $9 \%$ of the total radioactivity. The majority of the radioactivity inventory in the U.S. is contained in commercial spent nuclear fuel. In the U.S., the present policy is for the direct disposal of spent nuclear fuel; however, in France, England, Japan, and Russia, the spent nuclear fuel is reprocessed to reclaim fissile material for power generation and/or production of nuclear weapons. This reprocessing generates substantial volumes of high-level waste, most of which is destined for vitrification.

There are also several tens of tons of plutonium residues and scraps in the DOE complex, ${ }^{1}$ primarily at the Rocky Flats Plant in Colorado, the Hanford Site, and the Savannah River Site. This material was "stranded" in the plutonium processing facilities due to the sudden shutdown of the facilities at the end of the Cold War. The plutonium residues and scraps are in a wide variety of forms, including $\mathrm{Pu}$ dissolved in acid, rough pieces of metal, and nearly finished weapons parts. ${ }^{1,7}$ Similar quantities of plutonium residues and scraps are to be found in Russian weapons production facilities.

Under the first and second Strategic Arms Reduction Treaties (START I and II) and unilateral pledges 
made by the United States and the former Soviet Union and Russia, many thousands of nuclear weapons will be dismantled during the next decade. This will generate over one hundred metric tons of plutonium and many hundreds of tons of highly enriched uranium, both of which will require disposition. ${ }^{2,3,15}$ Thus, the fissile materials, whose separation and concentration generated the defense HLW, have become a new waste stream. Recent studies by the National Academy of Sciences ${ }^{2,3}$ and others ${ }^{16}$ have recommended consideration of vitrifying weapons-grade plutonium in a mixture with high-level radioactive waste as one of two "promising" options. Consequently, earlier assumptions that the nuclear waste glass would have a low actinide content and thus a low cumulative exposure to $\alpha$-decay radiation are no longer valid. Additionally, the durability of the waste form becomes a very important concern with the disposal of the fissile material, ${ }^{239} \mathrm{Pu}$ and its daughter ${ }^{235} \mathrm{U}$ (the halflives of ${ }^{239} \mathrm{Pu}$ and ${ }^{235} \mathrm{U}$ are $2.41 \times 10^{4}$ and $7.04 \times$ $10^{8}$ years, respectively ${ }^{17}$ ), because any degradation of the waste form due to radiation effects may lead to increased corrosion rates and subsequent nuclide transport and reconcentration that could conceivably lead to criticality in a repository. ${ }^{18-20}$ Glass compositions currently under development for immobilization of $\mathrm{Pu}$ at the Savannah River Site ${ }^{21}$ and Argonne National Laboratory ${ }^{22}$ are significantly different from the compositions that have been investigated for immobilization of high-level tank wastes, and it is proposed that 5 to $20 \mathrm{wt} \% \mathrm{Pu}$ be incorporated into these glass waste forms. For these novel glass compositions, there are no data on the effects of radiation on glass structure or properties, and, as discussed below, the lack of a fundamental scientific understanding inhibits the extrapolation of the limited existing data to new glass compositions and the equivalent higher radiation doses.

To the extent that the high-level defense or $\mathrm{Pu}$ containing radioactive wastes must be treated and solidified prior to final disposition, the effect of radiation on the waste form solids must be an important concern. One of the more important applications of the study of radiation effects in ceramics (vitreous and crystalline), during the late 1970s and early 1980s, was the effects of radiation on borosilicate glasses and crystalline ceramics for HLW immobilization. Radiation effects in HLW forms and related materials have been the subject of several workshops ${ }^{23,24}$ and reviews. ${ }^{25-32}$ In general, most of the studies on radiation effects in HLW glasses have been engineering test studies that generated little, if any, systematic understanding of radiation effects in HLW glasses. As a result, there has been little advancement in the understanding of radiation effects in HLW glasses over the past decade. ${ }^{32}$ Based on some of the data in these reviews, the post-disposal radiation effects to glass waste forms could be significant. For example, the cumulative $\alpha$-decay dose that is projected for DWPF and WVDP nuclear waste glasses reaches a value of $7.6 \times$ $10^{16} \alpha$-decay events/g in 500 years, ${ }^{30}$ while over the same time period, glasses containing 10 to $20 \mathrm{wt} . \%{ }^{239} \mathrm{Pu}$ will accumulate 3.6 to $7.2 \times 10^{18} \alpha$-decay events/g, ${ }^{33,34}$ nearly 50 to 100 times higher. In both these cases, the dose is well within the range for which important changes in physical and chemical properties are observed to occur in HLW glasses.

\section{B. Principles of radionuclide immobilization in glass}

Borosilicate glass is, at present, the waste form of choice for most nuclear waste compositions and for most countries (e.g., France, Great Britain, the United States, Japan, and China) that have high-level defense waste or high-level waste from reprocessing of commercial nuclear fuels. The selection of borosilicate glass was based mainly on four assumptions: (i) an anticipated ease of processing (glass frit and the waste are mixed, melted at relatively low temperatures, and poured into canisters); (ii) that the technology is well demonstrated for actual (radioactive) waste; (iii) that the glass as an aperiodic solid will easily accommodate wide variations in waste stream compositions which are extremely complex (20 to 30 component systems); and finally, (iv) that glass as an aperiodic solid will show only a minor response to the effects of radiation, especially from $\alpha$-decay events. Glass waste forms can be of a wide variety of compositions, including silicate glasses, borosilicate glasses, and phosphate glasses. ${ }^{35}$ In principle, radionuclides are evenly dispersed throughout the glass, although noble metal precipitates and, in some cases, crystalline oxide precipitates enriched in radionuclides may be present. Waste loadings (defense and commercial) are typically in the range of 10 to $30 \mathrm{wt} . \%$.

Assessments of the long-term performance of waste forms is rare; present performance assessments of radionuclide containment rely primarily on the geologic barriers (e.g., long travel times in hydrologic systems or sorption on mineral surfaces). The physical and chemical durability of the waste form, however, can contribute greatly to the successful isolation of radionuclides; ${ }^{36}$ thus, the effects of radiation on physical properties and chemical durability of waste forms are of great importance. This was illustrated recently in a performance assessment of zircon for Pu disposal. ${ }^{34}$ The changes in chemical and physical properties occur over relatively long periods of storage, up to $10^{6}$ years, and at temperatures that range from 100 to $300{ }^{\circ} \mathrm{C}$, depending on waste loading, age of the waste, depth of burial, and the repository-specific geothermal gradient. Thus, a major challenge is to effectively simulate high-dose radiation effects that will occur at relatively low-dose 
rates over long periods of time at elevated storage temperatures.

\section{PRINCIPLES OF RADIATION EFFECTS}

\section{A. Radiation sources}

The principal sources of radiation in HLW are $\beta$-decay of the fission products (e.g., ${ }^{137} \mathrm{Cs}$ and ${ }^{90} \mathrm{Sr}$ ) and $\alpha$-decay of the actinide elements (e.g., U, Np, $\mathrm{Pu}$, $\mathrm{Am}$, and $\mathrm{Cm}$ ), both of which lead to physical and chemical changes in the waste form. Beta-decay produces energetic $\beta$-particles, very low energy recoil nuclei, and $\gamma$-rays; whereas, alpha-decay produces energetic $\alpha$-particles (4.5 to $5.5 \mathrm{MeV}$ ), energetic recoil nuclei (70 to $100 \mathrm{keV}$ ), and some $\gamma$-rays. There also are minor contributions to the radiation field from spontaneous fission events of the actinides and from $\alpha$-neutron reactions. The rates of spontaneous fission and $\alpha$-neutron reactions are very low and do not significantly contribute to the overall effects of radiation; consequently, radiation effects from spontaneous fission are not considered in this summary. In general, $\beta$-decay is the primary source of radiation during the first 500 years of storage, as it originates from the shorter-lived fission products (e.g., the half-life of ${ }^{137} \mathrm{Cs}$ is 30.2 years ${ }^{17}$ and the half-life of ${ }^{90} \mathrm{Sr}$ is 28.8 years ${ }^{17}$ ). The $\beta$-decay of fission products is responsible for the high radioactivity, high self-heating rates, and elevated temperatures early in the history of waste form storage. Due to the long half-lives of the actinides and their daughter products (e.g., the half-lives of ${ }^{237} \mathrm{~Np},{ }^{239} \mathrm{Pu}$, and ${ }^{235} \mathrm{U}$ are $2.14 \times 10^{6}, 2.41 \times 10^{4}$, and $7.04 \times 10^{8}$ years, ${ }^{17}$ respectively), $\alpha$-decay is generally dominant at longer times. Figure 1 shows the cumulative beta and alpha decay events as a function of storage time that have been estimated for DWPF glass ${ }^{29,30}$

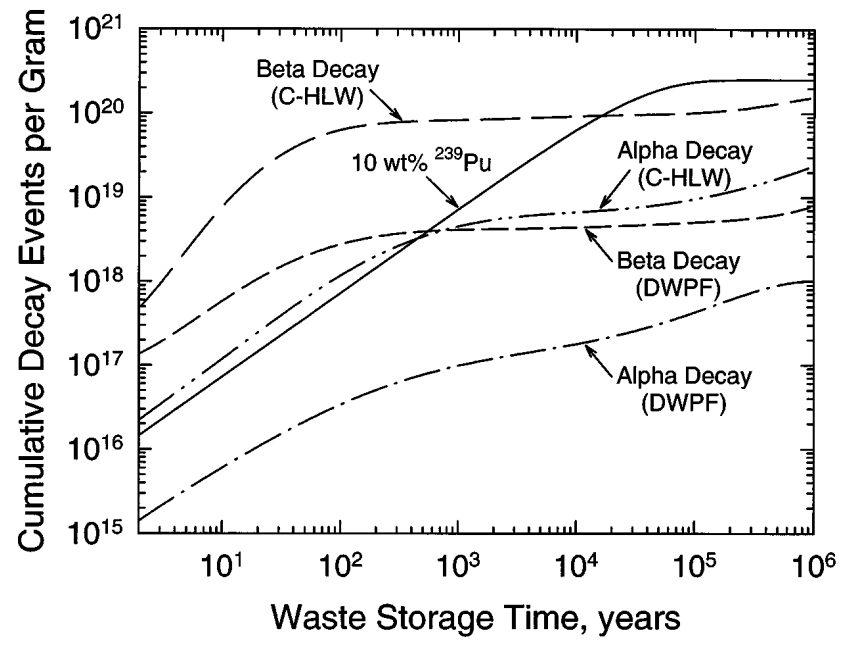

FIG. 1. Cumulative number of decay events per gram for DWPF glass, a commercial (C-HLW) nuclear waste glass, and a glass containing $10 \mathrm{wt} \%$ plutonium.

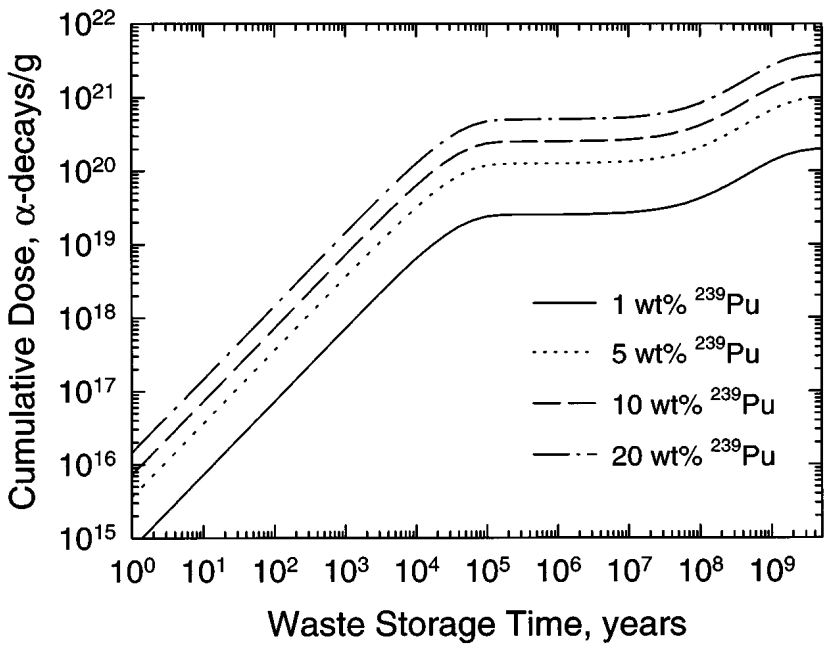

FIG. 2. Cumulative $\alpha$-decay dose as a function of plutonium loading and waste storage time.

and non-U.S. commercial HLW glass. ${ }^{25}$ The cumulative $\beta$-decay and $\alpha$-decay events for the WVDP glass are similar to those for DWPF glass. ${ }^{29,30}$ Also shown in Fig. 1 is the cumulative number of $\alpha$-decay events for a waste glass containing $10 \mathrm{wt} . \%{ }^{239} \mathrm{Pu},{ }^{33}$ which reaches significantly larger values relative to DWPF, WVDP, or non-U.S. commercial HLW glasses. The cumulative $\alpha$-decay events in glasses for ${ }^{239} \mathrm{Pu}$ immobilization reach a temporary plateau after 100,000 years, but increase over much longer time periods due to the ${ }^{235} \mathrm{U}$ decay series, as shown in Fig. 2 for several ${ }^{239} \mathrm{Pu}$ concentrations in a waste glass.

\section{B. Interaction of radiation with glass}

Beta and alpha decay affect waste glass through the interactions of the $\beta$-particles, $\alpha$-particles, recoil nuclei, and $\gamma$-rays with the glass. These interactions fall into two broad categories: the transfer of energy to electrons (ionization and electronic excitations) and the transfer of energy to atomic nuclei, primarily by ballistic processes involving elastic (billiard-ball-like) collisions. The total energy absorbed as a function of storage time for $\beta$-decay and $\alpha$-decay processes is shown in Fig. 3 for DWPF glass, ${ }^{29,30}$ non-U.S. commercial HLW glass, ${ }^{25}$ and a $10 \mathrm{wt} . \%{ }^{239} \mathrm{Pu}$ glass. ${ }^{33}$ The partitioning of the energy transferred into electronic excitations and into elastic nuclear collisions is an important process controlling the effects of radiation. For $\beta$-particles and $\gamma$-radiation, the energy transfer is dominated by ionization processes. For ions, such as $\alpha$-particles and recoil nuclei, this partitioning is governed by the relative velocity of the ions and that of the orbital electrons of the constituent ions of the glass. If the ion velocity is higher than that of the orbital electrons, ionization processes will dominate. However, if the particle velocity is below that 


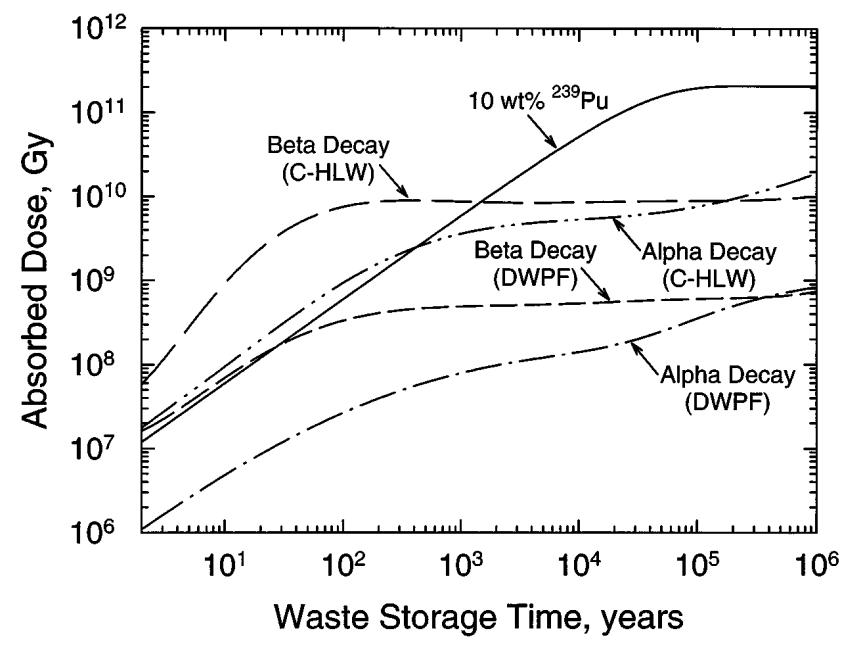

FIG. 3. Cumulative absorbed dose for DWPF, C-HLW, and $10 \mathrm{wt}$ \% plutonium glasses.

of the orbital electrons, the likelihood of ionization is small, and most of the energy will be transferred to the nucleus of the ion. A useful relation is that ionization processes dominate if the energy of the bombarding particle, expressed in $\mathrm{keV}$, is greater than its atomic weight, and elastic collision (Coulombic) interactions with atomic nuclei are predominant if the energy of the ion falls below this limiting approximation. Thus, an $\alpha$-particle with an atomic weight of 4 and energy ranging from 4.5 to $5.5 \mathrm{MeV}$ will predominately deposit its energy by ionization processes, while an $\alpha$-recoil ion with an atomic weight of 235 to 244 and energy 70 to $100 \mathrm{keV}$ will lose most of its energy in elastic collisions with the nuclei of atoms in the glass. In addition to the transfer of energy, the particles emitted through radioactive decay can themselves, in some cases, have a significant effect on the nuclear waste glass as a result of their deposition and accommodation in the glass structure.

\section{Ionization and electronic excitation}

The amount of energy absorbed through interactions of the emitted particles with the atomic nuclei is only a very small fraction of the total energy absorbed; consequently, the results in Fig. 3 also approximate the energy deposited into ionization and electronic excitations in the glasses. Energy loss by $\beta$-particles and $\alpha$-particles is predominately through Coulombic interactions. The interaction of $\gamma$-rays with matter is primarily through the photoelectric effect, Compton scattering, and pair production. The high-rate of energy absorption through ionization and electronic excitation from $\beta$-decay in HLW glasses and from $\alpha$-decay in $\mathrm{Pu}$ glasses can result in significant self-heating. The magnitude of the temperature increase depends on the rate of energy absorption, physical properties of the solid (e.g., its specific heat), thermal conductivity, and heat transfer to the surroundings. In the case of non-U.S. commercial HLW glass in a repository, self-heating from $\beta$-decay of the fission products can result in initial storage temperatures greater than $200{ }^{\circ} \mathrm{C}$, with temperatures falling below $150{ }^{\circ} \mathrm{C}$ several hundred years after emplacement. For defense HLW glass in the U.S., initial temperatures in the Yucca Mountain repository may be as high $250{ }^{\circ} \mathrm{C}$, depending on the storage density of the waste glass and spent fuel packages, but temperatures will decrease to less than $100{ }^{\circ} \mathrm{C}$ after several hundred years. ${ }^{37}$ Glasses incorporating high loading of weapons-grade $\mathrm{Pu}$ will experience similar temperatures in the repository at Yucca Mountain; however, the decrease in temperature may be slower due to additional self-heating from the decay of the long-lived Pu. Temperature in this range can profoundly affect the response of nuclear waste glasses to radiation effects.

In addition to self-heating, ionization and electronic excitations produce a large number of electron-hole pairs and can result in covalent and ionic bond rupture, charged defects, enhanced diffusion, and localized electronic excitations. Bond ruptures and localized electronic excitations can lead to the formation of nonbridging oxygen defects, local decomposition (e.g., formation of $\mathrm{O}_{2}$ ), and the permanent displacement of atoms due to the conversion of a localized electronic excitation into atomic motion (often referred to as radiolysis). The radiolytic displacement of atoms can be a very efficient process in glasses, producing significantly more atomic displacements than ballistic collisions.

\section{Ballistic processes}

Ballistic processes cause direct atomic displacements through elastic scattering collisions and are responsible for the atomic-scale rearrangement of the structure. Beta particles, because of their low mass, do not efficiently transfer energy to atomic nuclei and induce well-separated single displacement events only at high energies. The recoil nuclei ( $\beta$-recoils) produced in $\beta$-decay events are almost never energetic enough to be permanently displaced. Similarly, the emission of $\gamma$-rays results in the recoil of nuclei ( $\gamma$-recoils), which are also not sufficiently energetic to be permanently displaced for most decay products in HLW. In general, $\beta$-decay of the fission products in HLW produces on the order of 0.1 atomic displacements per $\beta$-decay event. The primary source of atomic displacements by ballistic processes in HLW and Pu glasses are the $\alpha$-particle and $\alpha$-recoil nucleus produced in an $\alpha$-decay event. The $\alpha$-particles emitted by actinide decay in HLW glasses have energies of 4.5 to $5.8 \mathrm{MeV}$, and the recoil nuclei $\alpha$-recoils) have energies of 70 to $100 \mathrm{keV}$. In the case of $\mathrm{Pu}$ glasses, a $5.2 \mathrm{MeV} \alpha$-particle and a $86 \mathrm{keV}{ }^{235} \mathrm{U}$ 
recoil are released by the decay of the ${ }^{239} \mathrm{Pu}$ ( $\alpha$-particles and $\alpha$-recoils of similar energies are released during the decay of the ${ }^{235} \mathrm{U}$ series).

The $\alpha$-particles dissipate most of their energy by ionization processes over a range of 16 to $22 \mu \mathrm{m}$, but undergo enough elastic collisions along their path to produce several hundred well-separated atomic displacements. The largest number of displacements occurs near the end of range of the $\alpha$-particles. The partitioning of energy loss between ionization and elastic collisions and the distribution of ballistically produced displaced atoms can be determined by Monte Carlo calculations using a computer code, such as TRIM. ${ }^{38}$ The results of such a calculation using TRIM-96 are illustrated in Fig. 4, where the positions of displaced oxygen ions and cations that result from a $5.2 \mathrm{MeV} \alpha$-particle in a borosilicate glass composition are shown on the $x-y$ plane. (The wide use of the TRIM code is due to its many years of use by the semiconductor industry where its predictions have been verified by many experimental determinations.)

The more massive but lower energy $\alpha$-recoil particle accounts for most of the total number of displacements produced by ballistic processes in HLW and Pu glasses. The $\alpha$-recoil loses nearly all of its energy in elastic collisions over a very short range (30 to $40 \mathrm{~nm}$ ), producing highly localized damage (displacement cascade or thermal spike) with 1000 to 2000 displacements. Such a displacement cascade for a ${ }^{235} \mathrm{U}$ recoil in a borosilicate glass is illustrated in Fig. 5. The density of energy deposited into the glass by an $\alpha$-recoil cascade is very high (up to $1 \mathrm{eV} /$ atom), occurs over a very short time $\left(<10^{-12} \mathrm{~s}\right)$, and can lead to local "melting."

In an $\alpha$-decay event, the $\alpha$-particle and $\alpha$-recoil particle are released in opposite directions and produce

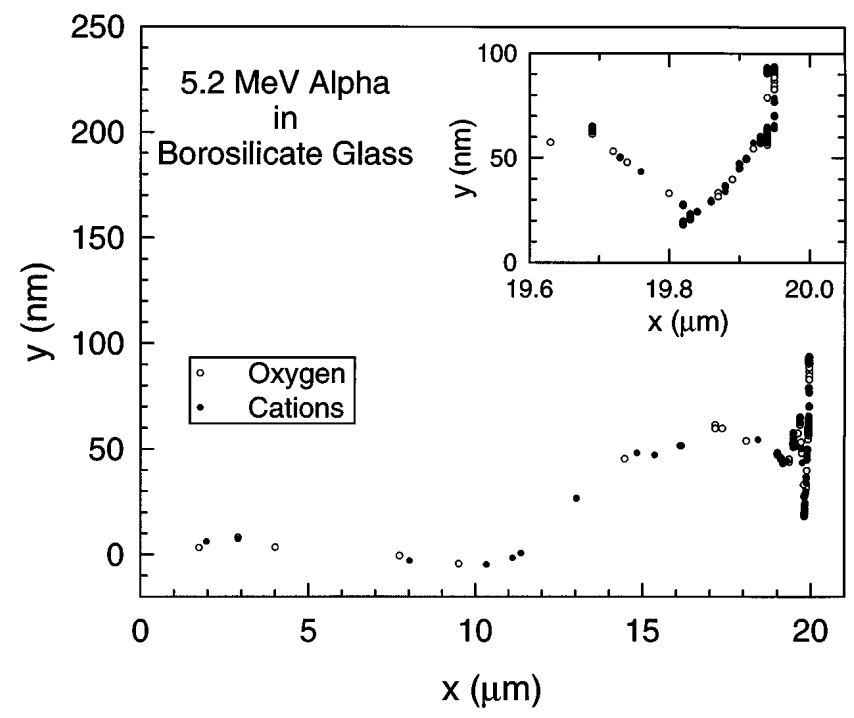

FIG. 4. Distribution of displaced atoms in the collision cascade of a $5.2 \mathrm{MeV} \alpha$-particle in borosilicate glass (calculated using TRIM-96).

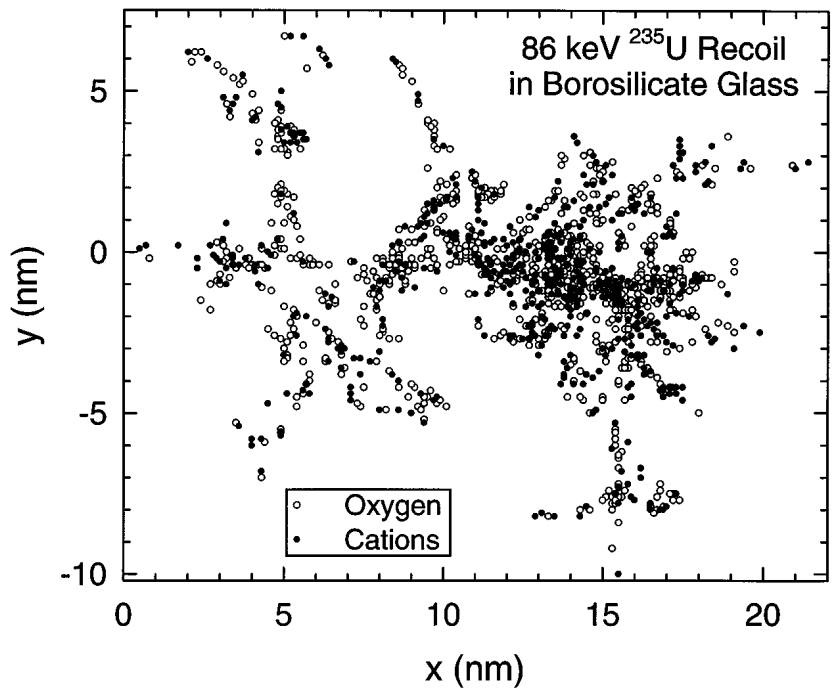

FIG. 5. Distribution of displaced atoms in a collision cascade of a $86 \mathrm{keV} \mathrm{U}$ recoil in borosilicate glass (calculated using TRIM-96).

distinct damage regions separated by several microns. Based on full cascade Monte Carlo calculations using TRIM-96, the average number of atomic displacements generated in a borosilicate glass by the $5.2 \mathrm{MeV}$ $\alpha$-particle and the $86 \mathrm{keV}{ }^{235} \mathrm{U}$ recoil released in the decay of ${ }^{239} \mathrm{Pu}$ are 380 and 1930 , respectively. The average number of displacements generated per $\alpha$-decay event by the decay of the actinides in HLW glass is expected to be similar and is estimated to be 2300 displacements per $\alpha$-decay event. This is significantly more than the 0.1 displacements generated per $\beta$-decay. The estimated number of displacements per atom (dpa) generated by $\beta$-decay and $\alpha$-decay in DWPF glass, a non-U.S. commercial HLW glass, and a 10 wt. $\%{ }^{239} \mathrm{Pu}$ glass are shown in Fig. 6 . The results in Fig. 6 clearly show the dominance of $\alpha$-decay events ( $\alpha$-particles and $\alpha$-recoils) in producing ballistic-type collision damage in glass waste forms (displacements from radiolytic processes are not included).

\section{Transmutations and gas production}

In addition to the energy transferred to the glass, $\beta$-decay and $\alpha$-decay also lead to transmutation of radioactive parent nuclei into different chemical elements that must be accommodated and may significantly impact the chemical properties of the glass. ${ }^{25,32}$ The principal source of transmutations in HLW are $\beta$-decay of the relatively abundant fission products, ${ }^{137} \mathrm{Cs}$ and ${ }^{90} \mathrm{Sr}$. Transmutation of these two elements is accompanied by changes in both ionic radius and valence. $\mathrm{Cs}^{1+}$ decays to $\mathrm{Ba}^{2+}$ with a decrease in ionic radius of $20 \%$, and $\mathrm{Sr}^{2+}$ decays to $\mathrm{Y}^{3+}$, which in turn decays to $\mathrm{Zr}^{4+}$ with a final ionic radius decrease of $29 \% .{ }^{39}$ In glasses for $\mathrm{Pu}$ immobilization, where the $\mathrm{Pu}$ concentration is high, the transmutation of 


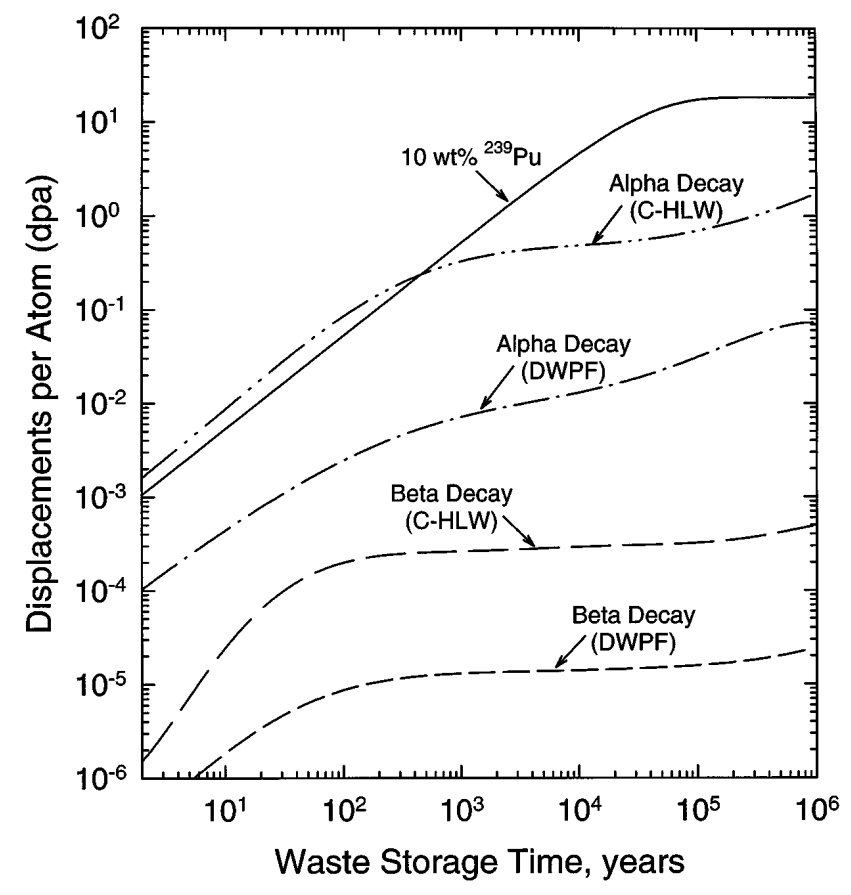

FIG. 6. Displacements per atom (dpa) from ballistic processes as a function of waste storage time for DWPF, C-HLW, and $10 \mathrm{wt}$ \% plutonium glasses.

${ }^{239} \mathrm{Pu}$ to ${ }^{235} \mathrm{U}$ (both of which are fissile) may also result in changes in valence states and ionic radius, which could impact long-term performance and safety [e.g., $\mathrm{U}^{6+}$ as the uranyl ion $\left(\mathrm{UO}_{2}\right)^{2+}$ is much more soluble than $\left.\mathrm{U}^{4+}\right]$.

Helium atoms, which result from the capture of two electrons by $\alpha$-particles, are also produced and must be accommodated in the glass interstitially, be trapped at internal defects, aggregate to form bubbles (or voids), or be released at the glass surface. ${ }^{25,30}$ For HLW, most of the $\mathrm{He}$ will be generated over long time periods near ambient temperature, and the concentration should not exceed 100 atomic parts per million (appm). In the case of glass waste forms for $\mathrm{Pu}$ immobilization and disposal, He concentrations can become quite large: 450 appm and 1.5 atom\% in 1000 and 100,000 years, respectively, for glasses containing $20 \mathrm{wt} . \%{ }^{239} \mathrm{Pu}$. These He concentrations are significantly above the solubility for $\mathrm{He}$ in borosilicate waste glasses, which is on the order of $2 \times 10^{22}$ atoms $/ \mathrm{m}^{3}(0.25 \mathrm{appm})$ at $400{ }^{\circ} \mathrm{C}$ and $1.7 \times$ $10^{5} \mathrm{~Pa}(\mathrm{He}) .^{40,41}$ Consequently, all of the He generated must be trapped at defects, collect into bubbles, or be released at surfaces.

In addition to $\mathrm{He}$ production from $\alpha$-decay, the evolution of molecular oxygen from a wide range of glasses irradiated with $20 \mathrm{keV}$ electrons was confirmed over 30 years ago using mass spectroscopy. ${ }^{42,43}$ The tendency of the glasses to evolve $\mathrm{O}_{2}$ under ionizing irradiation conditions showed a strong dependence on glass composition, with fused silica showing the lowest rate of $\mathrm{O}_{2}$ evolution. This radiolytic source of $\mathrm{O}_{2}$ can play an important role in the evolution of microstructure (Secs. III and IV).

\section{Irradiation techniques}

Since the effects of radiation will accumulate over very long time periods, the effects of radiation in HLW glasses have been studied using a broad range of accelerated irradiation techniques. These irradiation techniques and procedures have been described in detail previously, ${ }^{25,32}$ but are briefly reviewed here.

\section{Actinide-incorporation}

The long-term effects of $\alpha$-decay events have been simulated in a number of waste glass compositions ${ }^{25-28,32,44}$ by incorporating short-lived actinides, such as ${ }^{238} \mathrm{Pu}$ (half-life of 87.7 years ${ }^{17}$ ) or ${ }^{244} \mathrm{Cm}$ (half life of 18.1 years $\left.{ }^{17}\right)$ in sufficient concentrations $(0.2$ to $3 \mathrm{wt} . \%$ ) to achieve $10^{18}$ to $10^{19} \alpha$-decay events $/ \mathrm{g}$ in laboratory time periods of up to several years. This technique effectively simulates, at accelerated dose rates, the simultaneous $\alpha$-particle and $\alpha$-recoil effects that are expected over long periods of time $\left(10^{3}\right.$ to $10^{6}$ years $)$ for HLW waste glasses or over 100 to 1000 years for $\mathrm{Pu}$ glasses. The incorporation of short-lived actinides into waste forms in order to test the stability of waste forms to $\alpha$-decay damage has become a standard method (ISO 6962) approved by the International Organization for Standardization ${ }^{45}$ and is the basis for the DOE Materials Characterization Center's MCC-6 Method for the Preparation and Characterization of Actinide-Doped Waste Forms ${ }^{46}$ that has been used to prepare several Pu-doped HLW glasses. ${ }^{47}$ Phase separation and partial divitrification can result in nonhomogeneous distribution of actinides in actual nuclear waste glasses. These effects can be readily simulated using actinide incorporation techniques and appropriate processing to produce similar phase separation or crystallinity.

\section{Actinides in natural glasses}

Natural glasses do contain ${ }^{238} \mathrm{U},{ }^{235} \mathrm{U}$, and ${ }^{232} \mathrm{Th}$ and their daughter products. Unfortunately, natural glasses do not contain enough uranium and thorium to serve as natural analogues for radiation effects in waste form glasses because of the generally low doses that have been obtained. In volcanic glasses, the uranium content generally increases with the silica content; hence, basaltic glasses have uranium contents that range from $0.1 \mu \mathrm{g} / \mathrm{g}$ to a few $\mu \mathrm{g} / \mathrm{g}$, and silicic glasses (obsidians), from a few $\mu \mathrm{g} / \mathrm{g}$ to about $20 \mu \mathrm{g} / \mathrm{g}$. Despite these low uranium concentrations, fission tracks occur in sufficient abundance to allow dating of natural glasses. There are more than 400 successful age determinations on volcanic glasses which utilize fission track dating. Tektites (terrestrial 
impact glasses) have uranium contents on the order of a few $\mu \mathrm{g} / \mathrm{g}$, and more than 250 specimens have been dated utilizing fission tracks. The fission tracks represent an extreme in radiation damage caused by massive particles (fission fragments) of high energy (hundreds of $\mathrm{MeV}$ ) with the latent tracks being up to several tens of $\mathrm{nm}$ in length. The fission fragment yield in nuclear waste glasses is very much lower than that of alpha-decay events, and thus this is not a major damage mechanism. Still, fission tracks offer an opportunity for the study of track annealing in an aperiodic solid, ${ }^{48}$ and such results may be relevant to the evaluation of the persistence of damage tracks in nuclear waste glasses. There is, however, one instance in which a synthetic Th-doped borosilicate glass, 17 years in age, has been studied, and enhanced chemical reactivity of the damage tracks produced by the $\alpha$-recoil nuclei was clearly demonstrated. ${ }^{49}$ This phenomenon, differential etching of damage tracks, is well documented in naturally occurring minerals and glasses. ${ }^{50}$

\section{Charged-particle irradiation}

Charged-particle irradiation using electrons, protons, $\alpha$-particles, and heavy ions has been used to simulate and study radiation effects in HLW glasses. ${ }^{32}$ These techniques generally employ particle accelerators and high dose rates; consequently, very significant doses can be reached in short periods of time (e.g., minutes). Analysis of the results from such irradiations is difficult because the damaged areas are thin surface layers of restricted lateral extent. The high surface area can act as a sink for migrating defects, and electric field gradients may be generated along the electron or ion paths. Implanted layers also can change the characteristics of the target material as a result of compositional changes ${ }^{51}$ (e.g., $\mathrm{Pb}$ implantation). Still, $\alpha$-particle irradiation can be a good simulation of $\alpha$-particle damage, and heavy-ion (e.g., $\mathrm{Xe}, \mathrm{Pb}$ ) irradiation could provide a reasonable simulation of $\alpha$-recoil damage. In fact, the two techniques could be used simultaneous to study the effects of both $\alpha$-particles and $\alpha$-recoils on glass. Electron irradiations have generally been used to simulate and study the effects of ionization and electronic excitations from $\beta$-particles and $\gamma$-rays on glass. One disadvantage of charged-particle irradiations, particularly for simulating the damage from alpha-decay events, is that the damage is homogeneously distributed and does not simulate heterogeneous irradiation effects that may result from a non-homogeneous distribution of actinides or fission products.

\section{Gamma irradiation}

Gamma irradiation, utilizing ${ }^{60} \mathrm{Co}$ or ${ }^{137} \mathrm{Cs}$ sources, also has been used to simulate the effects of $\beta$-particles and $\gamma$-rays on glass. ${ }^{25,29-32}$ The advantage of this type of irradiation is that $\gamma$-rays are so penetrating that simulated HLW glasses can be irradiated in bulk and while sealed in containers; furthermore, the $\gamma$-rays provide a realistic simulation since they interact with the glass primarily through ejected photoelectrons. Dose rates on the order of $2.5 \times 10^{6} \mathrm{R} / \mathrm{h}$ are easily achieved. ${ }^{25}$ Most studies have focused on the effects of $\gamma$-rays on HLW glass corrosion, where the most important effect is the radiolytic decomposition of species such as nitrogen and carbon dioxide, which are present in air or dissolved in the water, leading to the formation of nitric and carboxylic acids. ${ }^{25-32}$

\section{Neutron irradiation}

Irradiation with neutrons has also been used to simulate and study radiation effects in HLW glasses. ${ }^{25,32}$ Fast neutrons, which dissipate their energy by ballistic processes, produce significant numbers of atomic displacements but only moderately simulate the effects of the ballistic interactions of $\alpha$-particles and $\alpha$-recoils. ${ }^{25}$ This technique provides no simulation of helium buildup from the $\alpha$-particles. Another approach ${ }^{52}$ that has been used with borosilicate glasses is irradiation in a thermal neutron flux to generate a $1.78 \mathrm{MeV} \alpha$-particle as a result of the high ${ }^{10} \mathrm{~B}(n, \alpha){ }^{7} \mathrm{Li}$ cross section. With this technique, high rates of He formation are possible, but this does not simulate the dense collision cascade of the $\alpha$-recoil particle. A third technique ${ }^{53}$ involves fission of fissile nuclides (e.g., ${ }^{235} \mathrm{U}$ ) in the glass by irradiation in a thermal neutron flux; the fission event results in very high-energy fission fragments that produce extensive regions of damage (i.e., fission tracks) that may or may not simulate ballistic damage from the $\alpha$ recoil particles. Such fission events provide an excellent simulation of spontaneous fission events in HLW and $\mathrm{Pu}$ glasses; however, as mention above, these events are so infrequent that they are unimportant as damage mechanisms. Similar to charged-particle irradiation, fast and/or thermal neutron irradiation produces nearly homogeneous damage that cannot simulate the nonhomogeneous distributions of actinides or fission products due to phase separation or crystallinity.

\section{STRUCTURE AND RADIATION EFFECTS IN GLASSES}

Many glasses proposed for HLW and Pu immobilization and disposal (e.g., DWPF glass) comprise approximately 50 wt. $\% \mathrm{SiO}_{2}$. Therefore, a knowledge of radiation effects in pure silica (i.e., amorphous forms of $\mathrm{SiO}_{2}$ ) and simple binary silicate glasses can give useful clues to the behaviors of HLW and Pu glasses to be expected at high radiation doses. The earliest observations of radiation effects in glasses were reported nearly 70 years ago by Curtiss ${ }^{54}$ and by Lind, ${ }^{55}$ 
who observed crazing and cracking in silica and Pyrex irradiated with $\alpha$-particles emitted by radium. Later experiments by Tuck $^{56}$ showed that such $\alpha$-particle damage leads to increased leach rates for both a sodalime glass and Pyrex. Although there have been many observations of irradiation-induced changes in properties of simple glasses (e.g., variations in refractive index, density, and mechanical properties),${ }^{57}$ the understanding of these macroscopic changes in structure is still not well developed. On the other hand, the families of radiation-induced point defects in pure silica and simple alkali silicate glasses are well understood from 40 years of study, principally by the technique of electron spin resonance (ESR). ${ }^{57,58}$

The current understanding of structure and radiation effects in simple and simulated nuclear waste glasses is briefly reviewed in this section. This review is not comprehensive but rather reflects the topics discussed by the panel in the deliberations designed to identify important scientific issues pertinent to radiation effects in nuclear waste form glasses.

\section{A. Structure of glasses}

Some description of the structure of network glasses is important for assessing the role of radiation effects in creating distinguishable structural rearrangements; in other words, how does one identify and describe a defect in an aperiodic solid. In the case of irradiated crystalline ceramics, one may unambiguously define a displaced atom, the point defect spectrum, and gross structural rearrangement (e.g., the formation of dislocation loops, metal colloids, and voids ${ }^{59}$ ). Without a reference lattice, as is the case for an aperiodic (glassy) solid, it is difficult to define an individual displaced atom or the gross structural rearrangements associated with a displacement cascade. One useful approach is to monitor a characteristic structural parameter, such as the $\mathrm{X}-\mathrm{O}-\mathrm{X}$ bond angle $(\mathrm{X}=$ network-forming elements $\mathrm{Si}, \mathrm{B}, \mathrm{Al}$, $\mathrm{P}$...) in oxide network glasses, that is independent of crystallinity. There is, for example, evidence that the $\mathrm{Si}-\mathrm{O}-\mathrm{Si}$ bond angle in vitreous $\mathrm{SiO}_{2}$ decreases by some $11^{\circ}$ after neutron and ion irradiation. ${ }^{60}$ Similar bond-angle changes have been observed in complex oxides, such as $(\mathrm{Ca}, \mathrm{Th}) \mathrm{ZrTi}_{2} \mathrm{O}_{7}$ (i.e., zirconolite), that experience a radiation-induced crystalline-to-aperiodic transformation due to $\alpha$-decay damage from the $\mathrm{U}$ and Th content. ${ }^{61}$ Spectroscopic measurements (EXAFS and XANES) show that the loss of long-range order in zirconolite is due to minor variations (less than $5^{\circ}$ ) in the metal-O-metal bond angle. Also, the nearest neighbor coordination sphere of the aperiodic state is essentially the same as that of the crystalline material, demonstrating the similarity of the structures in terms of the coordination polyhedra; the aperiodicity is the result of variations in the linkages between the nearest neighbor coordination polyhedra.

A more fundamental approach is to evaluate the overall structural topology of the glass, ${ }^{62}$ of which the $\mathrm{X}-\mathrm{O}-\mathrm{X}$ angle is a characteristic. In network glasses, the topological entity that appears is the ring, defined as a closed circuit along the edges of linked coordination polytopes (e.g., $\left[\mathrm{SiO}_{4}\right]$ tetrahedra in silicate glasses). The collection of lowest-order rings passing through a given site (together with associated coordination polytopes belonging to them) represents a characteristic structural entity, much as a space group does for a crystal. ${ }^{60}$ The ring complement can thus define the structural topology, and a change in the ring complement is a topologically identifiable change in the network structure. For example, in neutron-irradiated vitreous silica, both Raman $^{60}$ and neutron diffraction ${ }^{63,64}$ evidence point to an increase in the complement of 3-membered rings (i.e., rings containing three linked $\mathrm{SiO}_{4}$ tetrahedra). The association of two 3-membered rings per tetrahedron in a tetrahedral network has been shown to formally define a two-dimensional surface ${ }^{62}$; consequently, a significant increase in the number of 3 -membered rings implies formation of internal surfaces, such as would be expected to bound the voids or bubbles that are a persistent observation $^{32}$ in irradiated waste glasses.

Density is related to ring complement, ${ }^{65}$ and irradiation-induced changes in ring topology can be manifested as density changes. The correlation suggests that the structures of both vitreous and irradiationamorphized forms of silica are largely dominated by 6-membered rings, ${ }^{63}$ a distribution generally confirmed by computer ${ }^{66}$ and molecular dynamics ${ }^{67}$ models. The energetics of the silica intertetrahedral bond angle are fairly flat until 3-membered ring configurations $\left(130.5^{\circ}\right)$ are reached ${ }^{68}$; thus, a distribution of ring sizes is expected. Network structures, however, are not necessarily homogeneous, and it is possible to envisage heterogeneous structures in which delimited regions dominated by 6 -membered rings are linked to each other by larger and smaller rings. ${ }^{69}$ Larger rings are responsible for the higher density of the denser silica polymorphs ${ }^{65}$ because they can fold back on themselves, and the densification of vitreous silica by irradiation could arise from opening up of 6-membered rings to larger rings in regional boundaries.

Radiolytic damage processes, such as those proposed in silica ${ }^{70,71}$ result in a progressive accumulation of broken network linkages. Simple bond-switching has been demonstrated, at least heuristically, as a means of achieving topological disorder in monatomic tetrahedral networks ${ }^{72}$ and could operate as a subsequent rearrangement mode in silica ${ }^{73}$ and other networks. Radiolytic decomposition of $\mathrm{X}-\mathrm{O}-\mathrm{X}$ linkages to a critical threshold may result in the collapse of the network 
and its subsequent stochastic rebonding into altered topologies, just as the rigidity percolation threshold ${ }^{74}$ that is achieved in central-force networks by progressive bond removal leads to a sudden multiplication of floppy modes. Indeed, the maximum in detectable irradiation-induced oxygen vacancy $\left(E^{\prime}\right)$ centers in silica occurs at a dose corresponding to maximum rate of density change, ${ }^{60}$ when structural collapse and rebonding would likely re-form broken linkages. In dense collision cascades, it is possible, as an alternative, to consider wholesale restructuring as occurring according to local growth rules appropriate to either higher- or lowertemperature crystalline polymorphs, depending on the effective temperature of the cascade.

Ease of structural rearrangement in irradiated glasses is likely to correlate with a topological parameter like structural freedom, ${ }^{75}$ which depends on coordination polytopes and their modes of connectivity, just as suggested for amorphization of crystalline ceramics. ${ }^{62}$ The addition of network-modifying cations (such as $\mathrm{Na}$ ) is generally considered to disrupt network connectivity, but the coordination polytopes surrounding these cations are themselves linked, to each other and to the network, and their contribution to the structural constraint must be assessed. Some workers ${ }^{76}$ have suggested that the distribution of these network modifying cations may be inhomogeneous, in which case their influence on structural stability may be less than if uniformly dispersed. A fundamental question in glasses, which are already topologically disordered, is whether radiation-induced re-arrangement results in a topologically different structure (e.g., one with substantially different free energy). Ion-beam irradiation of lead pyrophosphate $\left(\mathrm{Pb}_{2} \mathrm{P}_{2} \mathrm{O}_{7}\right)$ glasses does induce a change in topological structure. ${ }^{77}$ Additionally, the preferential etching of $\alpha$-recoil tracks in glasses containing $\mathrm{Th}$ and $\mathrm{U}$ radionuclides ${ }^{49,50}$ suggests that there may be some difference, although density change, strain, or segregation within the tracks could account for the preferential chemical attack without the necessity to invoke topologically significant differences.

\section{B. Silica glass}

\section{Macroscopic changes}

As noted, $\alpha$-particle irradiation of silica glass leads to crazing and cracking. ${ }^{54,55}$ Primak et al. ${ }^{78}$ were the first to report the compaction (densification) and increase in refractive index of silica glass when subjected to a fastneutron fluence. The density of silica glass increases very rapidly to a value $3 \%$ greater than the unirradiated glass at a neutron fluence of $5 \times 10^{19} / \mathrm{cm}^{2}$; it then gradually decreases to a equilibrium density that is $2.7 \%$ greater than the unirradiated glass at a fluence of $\sim 4 \times 10^{20} / \mathrm{cm}^{2} .{ }^{79}$ Crystalline quartz subjected to the same fast-neutron fluence undergoes an expansion of $\sim 15 \%,{ }^{79,80}$ and asymptotically approaches the same density as the irradiated silica glass. ${ }^{57}$ Both materials probably share a common network structure at this saturation dose. Though amorphous, this radiation-induced structure must differ substantially from the structures of melt-quenched silica glasses. A similar compaction and increase in the refractive index of silica glass has been observed under ion irradiation, ${ }^{81-83}$ and compaction is also reported under electron ${ }^{84}$ and $\gamma^{84-86}$ irradiations. Both ballistic and ionization energy losses lead to densification of silica glass; however, ballistic processes are about a factor of 200 more efficient. ${ }^{81-83}$

Although silica glass normally compacts under irradiation, silica glasses impregnated with $\mathrm{H}$ expand when irradiated with $\gamma$-rays ${ }^{86}$ or with electrons. ${ }^{87,88}$ This so-called "impurity effect" has been associated with ionization processes because it can be produced by $18 \mathrm{keV}$ electrons, ${ }^{88}$ which cannot transfer sufficient energy to the network atoms to cause direct atomic displacement. This effect also is seen at low fluences under ion irradiation, but is overwhelmed by ballistic collisional processes with continuing irradiation to higher fluences. ${ }^{89}$ Shelby ${ }^{86}$ has suggested that this observed expansion is due to interstitial $\mathrm{OH}$, incorporated into the silica structure during processing, that inhibits occupation of such sites by $\mathrm{SiO}_{4}$ tetrahedral groups after bond-breaking.

Along with the increase in density and refractive index, the chemical etch rate of silica glass also increases with ion fluence. ${ }^{56,90}$ Although molecular oxygen is known to evolve radiolytically from silica glass irradiated with $20 \mathrm{keV}$ electrons, ${ }^{42}$ bubbles are not observed to form in silica glass under ion and electron irradiation to high fluences. ${ }^{91}$ Irradiation-induced stored energy of up to $800 \mathrm{~J} / \mathrm{g}(0.2 \mathrm{eV} /$ atom $)$ have been reported ${ }^{92}$ for silica glass.

In a review of radiation effects in silica glass, Devine $^{60}$ has shown that the concentration of the irradiation-induced oxygen-vacancy $\left(E^{\prime}\right)$ center saturates before significant densification occurs; this behavior is illustrated in Fig. 7. With respect to the structural modifications, Devine ${ }^{60}$ suggests that the densification $(2.5-3 \%)$ and the large bond-angle changes $\left(\sim 10^{\circ}\right)$ require the formation of large voids, such as can be attained by the structural change from a predominantly 6-membered ring structure to a 3-membered type; the latter is typical of films deposited at high temperature and quenched (CVD deposition at $300{ }^{\circ} \mathrm{C}$ ). ${ }^{93}$ A Raman study of ion-implanted silica ${ }^{94}$ showed the development of the $\mathrm{D}_{2}$ band at $605 \mathrm{~cm}^{-1}$ that is due to the 3-membered ring structure.

\section{Point defects}

The idealized structure of "defect-free" glassy silica is a "continuous random network" (CRN), wherein each 


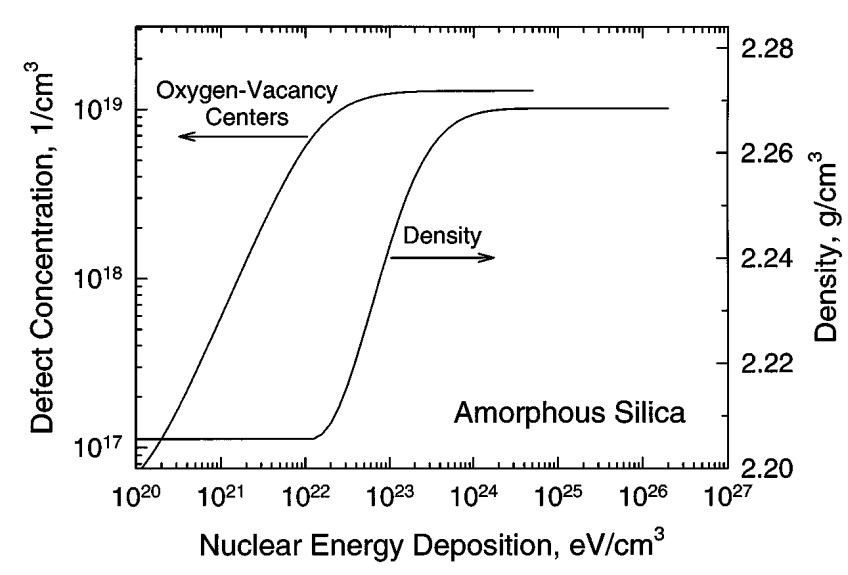

FIG. 7. Dependence of oxygen-vacancy center concentration and density on deposited nuclear (ballistic) energy in ion-irradiated amorphous silica (based on Devine ${ }^{60}$ ).

silicon is tetrahedrally bonded to 4 oxygens, and (in pure silica) each oxygen is bonded to two silicons. $\mathrm{X}$-ray and neutron diffraction data for silica glasses can be explained in terms of CRN-type models. ${ }^{95}$ A point defect in silica may comprise a group of perhaps 2 to 10 atoms present in a configuration qualitatively different from any configurations found in the idealized CRN. An oxygen-centered portion of the ideal network can be represented by the notation $\equiv \mathrm{Si}-\mathrm{O}-\mathrm{Si} \equiv$, where the notation " $\equiv$ " represents three bonds to other oxygens in the glass network. Structures probed by ESR are confined to those which are paramagnetic, i.e., those binding an unpaired electron (denoted by "." in the chemical notations used below).

A neutral oxygen vacancy in silica can be represented $\equiv \mathrm{Si}-\mathrm{Si} \equiv$. As implied by this notation, there is likely to be a chemical bond between the two silicons adjoining the vacancy site. The paramagnetic versions of the oxygen vacancy are called $E^{\prime}$ centers. ${ }^{96,97}$ One of the positively charged variants in amorphous $\mathrm{SiO}_{2}$, the $E^{\prime} \gamma$ center, ${ }^{98}$ is represented $\equiv \mathrm{Si} \cdot \mathrm{Si} \equiv$, where the unpaired electron is depicted as residing on the lefthand silicon, so that the positive charge formally resides on the right-hand silicon. (This "asymmetric relaxation" model ${ }^{99-101}$ was originally developed to explain the ESR characteristics of the analogous $E_{1}^{\prime}$ center in crystalline quartz.) When silica glass (or even crystalline quartz) is exposed to a fast-neutron fluence of $\sim 10^{20} / \mathrm{cm}^{2}$ or an ionizing dose of $\sim 10^{10} \mathrm{~Gy}$, the measured numbers of $E^{\prime}$ centers saturate at $\sim 1$ per thousand silicons. ${ }^{102}$ The numbers of electrostatically neutral, nonparamagnetic oxygen vacancies induced by these irradiations are larger, perhaps by an order of magnitude or more. Though the nonparamagnetic oxygen deficiency centers cannot be counted by ESR, they can be detected optically as an absorption band peaking near $248 \mathrm{~nm} .{ }^{103-106}$ Correlations have been established between the optical bleaching of the 248-nm band and the appearance of $E^{\prime}$ centers, ${ }^{104,106}$ consistent with the view that electrons can be optically detached from neutral oxygen vacancies, yielding $E^{\prime}$ centers:

$$
\equiv \mathrm{Si}-\mathrm{Si} \equiv \longrightarrow \equiv \mathrm{Si} \cdot \mathrm{Si} \equiv+e^{-} \text {. }
$$

Oxygen vacancies in silica may be created either by elastic collisions with energetic nuclear particles or radiolytically by decay of self-trapped excitons (bound electron-hole pairs created by ionizing radiation, such as $\gamma$-rays). ${ }^{107-110}$ A significant conclusion of careful ESR studies by many workers ${ }^{109,111-113}$ is that the displaced oxygen atoms move to interstitial positions, where they readily dimerize to form molecular oxygen. Upon heating to $\sim 200{ }^{\circ} \mathrm{C}$, this interstitial $\mathrm{O}_{2}$ has been shown to diffuse through the network and react with $E^{\prime}$ centers according to:

$$
\equiv \mathrm{Si} \cdot \mathrm{Si} \equiv+\mathrm{O}_{2} \longrightarrow \equiv \mathrm{Si}-\mathrm{O}-\mathrm{O} \cdot \mathrm{Si} \equiv .
$$

The fragment $\equiv \mathrm{Si}-\mathrm{O}-\mathrm{O} \cdot$ is a second fundamental defect species in silica and is known as the bonded peroxy radical. ${ }^{114}$ Any displaced oxygen that does not react according to Eq. (2) either remains as interstitial $\mathrm{O}_{2}$ molecules or else reacts with neutral oxygen vacancies to form (nonparamagnetic) peroxy-linkages, $\equiv \mathrm{Si}-\mathrm{O}-\mathrm{O}-\mathrm{Si} \equiv$ :

$$
\equiv \mathrm{Si}-\mathrm{Si} \equiv+\mathrm{O}_{2} \longrightarrow \equiv \mathrm{Si}-\mathrm{O}-\mathrm{O}-\mathrm{Si} \equiv .
$$

Thus, there are at least 0.5 oxygen-oxygen bonds for every thousand silicon atoms, complementing twice that many silicon-silicon bonds, at the fast neutron fluence for saturation. This interstitial $\mathrm{O}_{2}$ is the likely source of the radiolytic $\mathrm{O}_{2}$ released under the $20 \mathrm{keV}$ electron irradiations previously noted. ${ }^{42}$

A third elementary defect center in silica is the nonbridging-oxygen hole center (NBOHC), ${ }^{115}$ a configuration represented by the notation $\equiv \mathrm{Si}-\mathrm{O} \cdot$. Though the NBOHC can have several possible origins, it is most easily understood as resulting from radiolysis of a hydroxyl group:

$$
\equiv \mathrm{Si}-\mathrm{O}-\mathrm{H} \longrightarrow \equiv \mathrm{Si}-\mathrm{O} \cdot+\mathrm{H}^{0} \text {. }
$$

An example of a neutral $E^{\prime}$ center, denoted $E_{\beta}^{\prime}$, results when a radiolytic hydrogen atom [originating, e.g., in the reaction represented by Eq. (4)] reacts with a neutral oxygen vacancy ${ }^{98,116}$ :

$$
\equiv \mathrm{Si}-\mathrm{Si} \equiv+\mathrm{H}^{0} \longrightarrow \equiv \mathrm{Si} \cdot \mathrm{H}-\mathrm{Si} \equiv .
$$

Numerous species of defect centers associated with the elements boron, ${ }^{117}$ germanium, ${ }^{118}$ and phosphorus ${ }^{119}$ have been well characterized by ESR studies of otherwise pure silica doped with these elements individually. For comparable doses, the defects associated with these substitutional impurities tend to outnumber by 1 to 2 
orders of magnitude the $E^{\prime}$ centers, peroxy radicals, and NBOHC's observed in high-purity silica.

\section{Alkali silicate glasses}

\section{Macroscopic changes}

Ion irradiation of $\mathrm{Na}_{2} \mathrm{O}-3 \mathrm{SiO}_{2}$ glass results in expansion at low fluences and compaction at higher fluences that scales with the energy lost by ionization processes. ${ }^{120}$ In addition, ion ${ }^{83,121}$ and electron ${ }^{122,123}$ irradiation of alkali silicate glasses induces alkali ion migration that modifies the glass composition in the irradiated region. Such irradiation-induced alkali depletion can bring about phase separation and low-temperature crystallization, as observed in $\mathrm{Li}_{2} \mathrm{O}-2 \mathrm{SiO}_{2}$ glass. ${ }^{83} \mathrm{In}-$ creased $\mathrm{O}_{2}$ evolution is observed in electron-irradiated soda glasses relative to silica glass, ${ }^{42}$ and irradiation of a $0.07 \mathrm{Na}_{2} \mathrm{O}-0.93 \mathrm{SiO}_{2}$ glass with $1.5 \mathrm{MeV}$ electrons at $200{ }^{\circ} \mathrm{C}$ results in the formation of bubbles. ${ }^{124}$

\section{Point defects}

The defect centers induced in complex silicate (and borate) glasses involving alkali or alkaline-earth modifier oxides are created at rates which are higher by 1 to 3 orders of magnitude than those observed in monocomponent $\mathrm{SiO}_{2}\left(\right.$ or $\mathrm{B}_{2} \mathrm{O}_{3}$ ) glasses. This outcome is presumed to reflect the existence of many more electron and hole trapping sites in the complex glasses than are found in the pure network glasses.

Radiation-induced defects in simple alkali silicate glasses include two types of nonbridging-oxygen hole centers, denoted $\mathrm{HC}_{1}$ and $\mathrm{HC}_{2} \cdot{ }^{125-128}$ The former is analogous to the NBOHC appearing in Eq. (4), if one pictures an alkali atom substituted for the hydrogen. $\mathrm{HC}_{2}$ is similar, except that it involves two nonbridging oxygens on the same silicon. ${ }^{126,128}$ These HC-type defects are thought to be created by a process wherein a free hole first traps at $\mathrm{a} \equiv \mathrm{Si}-\mathrm{O}^{-} \mathrm{Alk}^{+}$site. The alkali ion $\left(\mathrm{Alk}^{+}\right)$is then free to diffuse away to the site of a trapped electron, where it stabilizes the latter. Based on ESR studies of alkali borate glasses, ${ }^{129}$ it is believed that electrons and alkali ions trap sequentially at such sites forming clusters that become increasingly stable as their sizes increase. Although it has not been explicitly demonstrated, it seems possible that under sufficiently high radiation doses, such alkali clusters may grow into macroscopic colloids, analogous to processes known to take place in $\mathrm{NaCl} .{ }^{130}$

Some $E^{\prime}$-type centers are observed in irradiated alkali silicate (and borate) glasses, although their numbers are relatively fewer that those of the other centers mentioned. ${ }^{127}$ These $E^{\prime}$ centers are believed to be of the electrostatically neutral type, understandable by substituting $\mathrm{Alk}^{0}$ for $\mathrm{H}^{0}$ in Eq. (5). Some bonded peroxy radicals have been revealed in the ESR spectra after the irradiated potassium silicate samples were annealed at $\sim 270{ }^{\circ} \mathrm{C}$ to diminish the intensities of the overlapping $\mathrm{HC}_{1}$ and $\mathrm{HC}_{2}$ signals. ${ }^{127}$ When these potassium silicate glass samples $\left(\gamma\right.$-irradiated to doses $\left.\sim 10^{6} \mathrm{~Gy}\right)$ were annealed to $\sim 310{ }^{\circ} \mathrm{C}$, the bonded peroxy radical centers also disappeared. The remaining ESR spectral features were unambiguously attributed to unbonded superoxide $\left(\mathrm{O}_{2}{ }^{-}\right)$and ozonide $\left(\mathrm{O}_{3}{ }^{-}\right)$ions. ${ }^{127}$ The observed superoxide-ion ESR spectrum is believed to be characteristic of $\mathrm{O}_{2}{ }^{-}$ions in a disordered alkali peroxide matrix $^{58}$ (presumably $\mathrm{K}_{2} \mathrm{O}_{2}$ in the studied example). Here, then, is ESR evidence for a radiation-induced decomposition of simple potassium silicate glasses into oxygen-rich peroxide phases on one hand and chemically reduced phases on the other. The reduced phases presumably comprise $\mathrm{SiO}_{x}(x<2)$ or alkali metal colloids, or both. There are well known tendencies ${ }^{131}$ for alkali peroxides to disproportionate into the monoxide $\left(\mathrm{Alk}_{2} \mathrm{O}\right)$ and the superoxide $\left(\mathrm{AlkO}_{2}\right)$, and for the superoxides in turn to disproportionate into the peroxides and $\mathrm{O}_{2}$ molecules. The appearance of ozonide ions is also predicted in the course of these disproportionation sequences. ${ }^{131}$ Thus, this series of reactions could be the source of the oxygen molecules suggested to be the cause of radiation-induced bubbles observed in simulated nuclear waste glasses. ${ }^{124,132-135}$

\section{Borosilicate glasses}

\section{Macroscopic changes}

Shelby ${ }^{86}$ measured the effect of $\gamma$-irradiation on the density, refractive index, thermal expansion, and helium permeability of several commercial borosilicate glass compositions. Compaction up to $1 \%$ was observed in the glasses after irradiation to $10^{8} \mathrm{~Gy}$. The refractive index increased with dose and the change in index was linearly proportional to the change in density. The thermal expansion coefficient decreased with dose and was linearly proportional to the change in density. The helium permeability was unaffected by $\gamma$-irradiation to $10^{8} \mathrm{~Gy}$.

In alkali borosilicate glasses, the high concentration of alkalis generally "clogs up" the interstitial sites, so that the initial effect of ion irradiation is to cause expansion. The fluence regime over which this expansion occurs is proportional to the alkali content of the glass. ${ }^{120}$ Since the alkali content in the many borosilicate glasses is known to be nonhomogeneously distributed (phase separated), ${ }^{136}$ expansion and compaction are associated with alkali-rich and alkali-depleted regions of the glass. Compaction eventually dominates, as in fused silica, after the expansion in the alkali-rich phase is saturated.

Utilizing cantilever-beam methodology and 0.5 to $4.0 \mathrm{MeV} \mathrm{Xe}$ ions, Snoecks and colleagues ${ }^{137,138}$ investigated the energy dependence of the lateral stress 
(volume change) in irradiated Na-borosilicate glasses. Compaction was observed at low energies (0.5 to $1.0 \mathrm{MeV}$ ), similar to the results of Arnold ${ }^{89,120,139}$; however, at higher energies (3.0 to $4.0 \mathrm{MeV}$ ), expansion occurred. These results suggest that between $1.0 \mathrm{MeV}$ and $3.0 \mathrm{MeV}$ there may be a threshold in the electronic stopping power for expansion in Na-borosilicate glasses under Xe irradiation. The electronic stopping power for $2.0 \mathrm{MeV} \mathrm{Xe}$ ions is about $1.5 \mathrm{keV} / \mathrm{nm}$ (based on TRIM-96) in these glasses, which is similar in magnitude to the electronic stopping power threshold $(2.3 \mathrm{keV} / \mathrm{nm})$ reported for anisotropic expansion in $\mathrm{SiO}_{2}$ thin films irradiated with Xe ions. ${ }^{140,141}$ Such a threshold may not be relevant for nuclear waste glasses, since the electronic stopping powers for the $\alpha$-particles and recoil nuclei emitted by alpha decay will not exceed $0.5 \mathrm{keV} / \mathrm{nm}$. It was also observed in these Na-borosilicate glasses ${ }^{137}$ that compaction (up to $0.12 \%$ ) occurred slowly with time when the ion beam was turned off for both initially compacting $(1 \mathrm{MeV})$ and expanding $(4 \mathrm{MeV})$ conditions. This was interpreted as a relaxation of the network due to annihilation of defects, possibly $\mathrm{O}$-vacancies.

Significant evolution of $\mathrm{O}_{2}$ from commercial borosilicate glasses irradiated with $20 \mathrm{keV}$ electrons has been measured. ${ }^{42,43}$ Oxygen bubble formation in high and low $\mathrm{Na}_{2} \mathrm{O}$ borosilicate glasses has been observed as a result of irradiation with $1 \mathrm{MeV}$ electrons ${ }^{135}$; the peak swelling temperature was $150{ }^{\circ} \mathrm{C}$ in the high $\mathrm{Na}_{2} \mathrm{O}$ glass and $325{ }^{\circ} \mathrm{C}$ in the low $\mathrm{Na}_{2} \mathrm{O}$ glass. Bubble formation in these glasses was preceded by the migration of $\mathrm{Na}$ away from the center of the irradiated region to the periphery. Leach tests indicated higher leach rates for the regions containing bubbles.

\section{Point defects}

Borosilicate glasses are expected to exhibit families of radiation-induced defect centers similar to those described for silica and alkali silicate glasses, plus a group of analogous defects which have been elucidated in simple alkali borate glasses. ${ }^{58,142,143}$ However, to date no studies have been conducted which indicate whether simple (or complex) borosilicate glasses are also subject to radiation-induced disproportionation into peroxides, superoxides, and ozonides.

\section{E. Simulated waste glasses}

The effects of radiation in nuclear waste glasses are complex, and the fundamental understanding of the radiation damage processes and available data are limited. The high-radiation environment provided by the $\alpha$-decay and $\beta$-decay of radionuclides in nuclear waste can affect radionuclide release to the biosphere through radiation-induced physical and chemical changes in the nuclear waste glass at both the atomic and macroscopic levels. Several comprehensive reviews ${ }^{25-32}$ of radiation effects in nuclear waste glasses provide excellent technical assessments. There are no data on the nature of intrinsic point defects or irradiation-induced point defects in actual or simulated nuclear waste glasses; however, glasses for HLW and Pu immobilization are expected to exhibit families of radiation-induced defect centers similar to those described for simple glasses. The only data available on simulated waste glasses are of measured macroscopic changes. These changes are briefly described below. More detailed information can be found in the reviews ${ }^{25-32}$ and in the discussions of specific issues (Sec. IV).

\section{Volume changes}

Radiation effects from $\alpha$-decay in actinide-doped simulated nuclear waste glasses results in either expansion or compaction of the glass structure. The macroscopic volume changes, $\Delta V / V_{O}$, generally follow an exponential dependence on dose, $D$, of the form:

$$
\Delta V / V_{O}=A[1-\exp (-B D)],
$$

where $A$ is the volume change at saturation, and $B$ is the amount of glass damaged per unit dose. For a large range of glasses studied in the United States ${ }^{25,29,30,32,44}$ and Europe, ${ }^{28,144}$ the volume changes normally reach an apparent plateau that is within the range of $\pm 1.2 \%$ at a dose of 1 to $2 \times 10^{18} \alpha$-decays/g $\left(1 \times 10^{9} \mathrm{~Gy}\right)$. This behavior is illustrated in Fig. 8 for several actinide-doped nuclear waste glasses studied at the Pacific Northwest National Laboratory and the Savannah River Site. Recent studies of actinide-doped glasses in Japan ${ }^{145,146}$ show irradiation-induced expansions of similar magnitude for similar doses. In one of these studies, ${ }^{145}$ the volume expansion determined by density measurements ranged from 0.4 to $0.6 \%$ and was in excellent agreement with

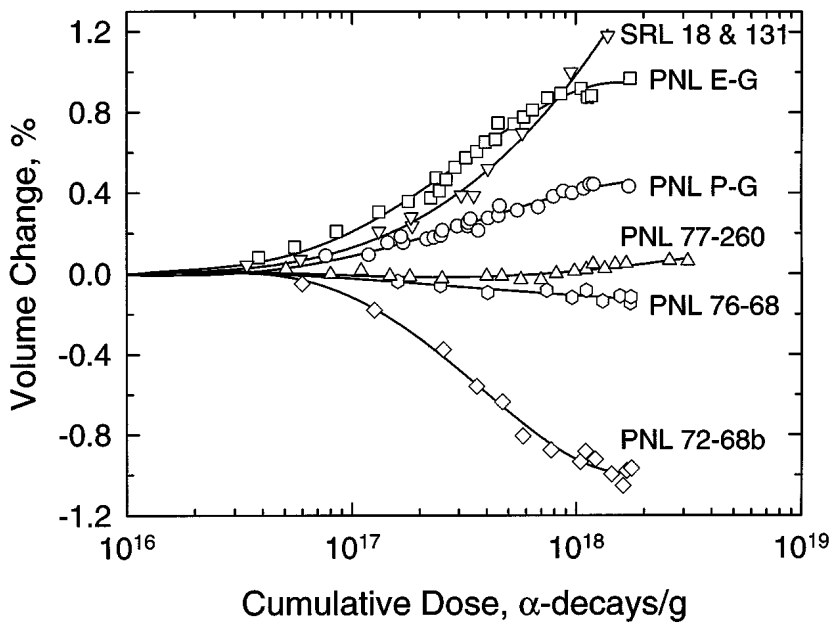

FIG. 8. Volume changes in several actinide-doped nuclear waste glasses studied at the Pacific Northwest National Laboratory ${ }^{25}$ and the Savannah River Site. ${ }^{44}$ 
the volume change $(0.51 \%)$ determined from the measured size and concentration of irradiation-induced bubbles. These bubbles may contain He from the $\alpha$-decay event or radiolytically produced oxygen. The volume expansion and compaction of neutron, ${ }^{147,148} \gamma$-ray, ${ }^{29,44,84,85}$ ion, ${ }^{89}$ and electron ${ }^{84}$ irradiated nuclear waste glasses are also within the bounds observed for the actinide-doped glasses. Manara et al. ${ }^{135,149}$ and Sato et al. ${ }^{85}$ have reported swelling up to $50 \%$ when bubbles formed during electron irradiation. In the simulated waste glasses, there is a general tendency for expansion in glasses with high alkali/Si ratios and compaction in glasses with low alkali/Si ratios. ${ }^{32}$ Another point of view, offered by Stoneham, ${ }^{150}$ is that the density changes in complex waste glasses are due to a radiation-enhanced equilibration to the ideal glass density for the glass composition. This, of course, assumes that bubbles do not form.

The effect of irradiation temperature on volume change has been studied in only one simulated waste glass (VG 98/3) doped with ${ }^{238} \mathrm{Pu}^{144}$; in that study, the rate of expansion at $130{ }^{\circ} \mathrm{C}$ was less than that at $20{ }^{\circ} \mathrm{C}$. The thermal recovery of radiation-induced volume changes in several ${ }^{238} \mathrm{Pu}$-doped waste glasses also has been studied, and recovery rate constants for the glasses have been determined. ${ }^{144}$ The rate constant for the glass VG 98/3 was used in a simple model to calculate the volume changes at $130{ }^{\circ} \mathrm{C}$; the calculated values were much smaller than the measured values, suggesting that the model (based on first-order recovery kinetics) may be oversimplified. No further work on the temperature dependence of volume changes in waste glasses has been reported.

Based on these limited data, it is impossible to determine conclusively whether the volume changes induced by $\alpha$-decay are due to ballistic or ionization processes. Ion-irradiation studies of Arnold ${ }^{89,121}$ have indicated that ionization processes are the dominant mechanism for producing volume changes in borosilicate nuclear waste glasses, and this issue will be discussed in greater detail (Sec. IV). In the absence of bubble formation, the magnitudes of the above volume changes are small; however, the data do not extend to the much higher dose range that will be experienced by glasses used for $\mathrm{Pu}$ disposition.

\section{Stored energy}

The interactions of radiation with nuclear waste glasses can result in the storage of latent energy associated with the changes in structure and bonding that is released as heat at elevated temperatures. Studies on actinide-doped simulated nuclear waste glasses at the Pacific Northwest National Laboratory, ${ }^{25,151}$ AEREHarwell, ${ }^{152}$ and under a collaborative European Communities program ${ }^{153}$ indicate that $\alpha$-decay can result in a rapid increase in stored energy that saturates at values generally less than $150 \mathrm{~J} / \mathrm{g}(\sim 0.03 \mathrm{eV} /$ atom $)$ at a dose of 0.1 to $0.3 \times 10^{18} \alpha$-decays/g $\left(10^{8} \mathrm{~Gy}\right)$, as illustrated in Fig. 9. A comparison of the energy and volume change results indicates that the saturation in stored energy occurs at a much lower dose than for the volume changes, as illustrated in Fig. 10 for one simulated waste glass composition. Similar behavior has been observed for silica glass (Fig. 7) and for all the simulated waste glasses studied, regardless of whether there is compaction or expansion. This behavior indicates that the defects giving rise to the stored energy precede the network rearrangements that manifest as volume changes.

The effect of irradiation temperature on stored energy has also been studied in only one glass (PNL 72-68) doped with ${ }^{244} \mathrm{Cm}$; the stored energy in this glass decreased linearly with irradiation temperature and was completely absent at $350{ }^{\circ} \mathrm{C} .{ }^{151}$ Thermal recovery of the stored energy in several ${ }^{244} \mathrm{Cm}$-doped glasses has

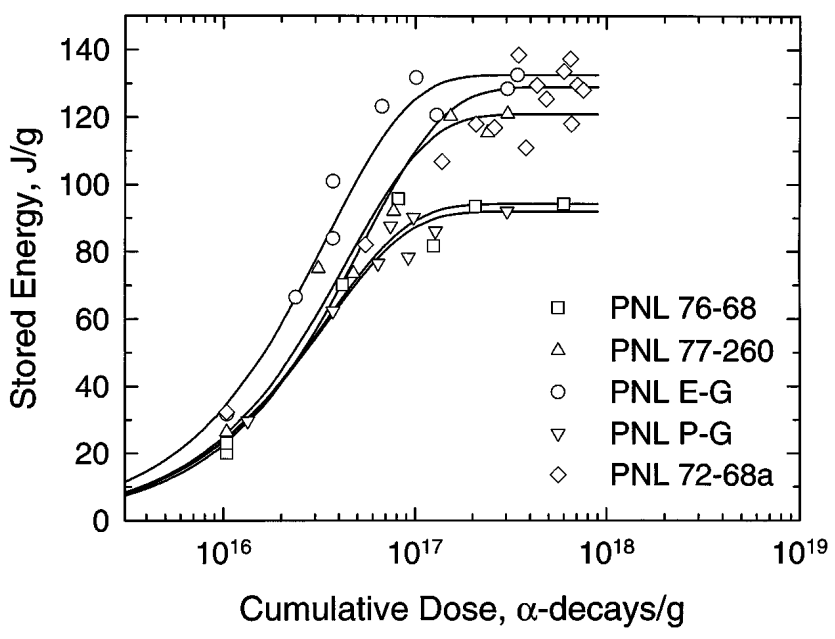

FIG. 9. Stored energy in several $\mathrm{Cm}$-doped simulated waste glasses. ${ }^{25}$

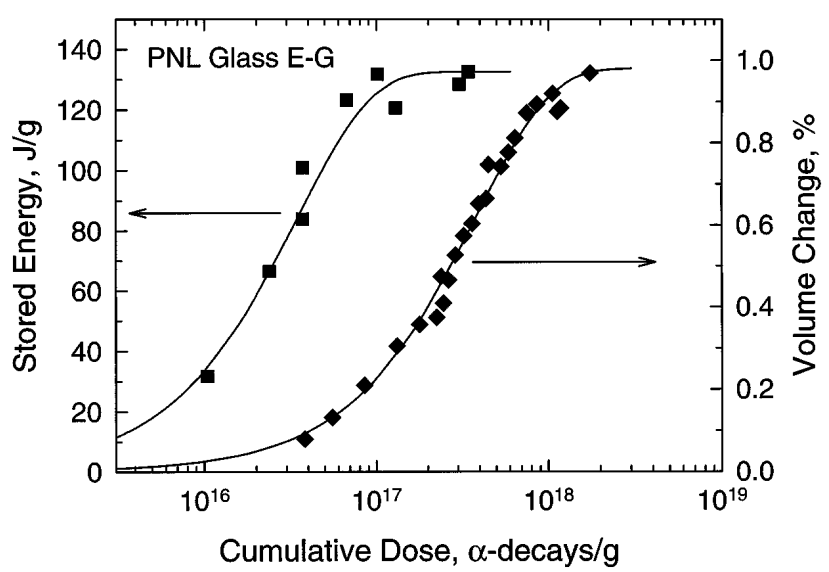

FIG. 10. Stored energy and volume change in a simulated waste glass as a function of cumulative dose. 
also been investigated, and the results show a single (nearly linear) recovery stage that is similar for all the glasses, with full recovery occurring at $360{ }^{\circ} \mathrm{C} .{ }^{25}$ The similarity of the temperature dependence for stored energy accumulation and recovery suggests that the accumulation of stored energy (defects) is controlled by the defect recovery kinetics.

\section{Helium accumulation}

As noted earlier, $\mathrm{He}$ atoms will accumulate as a result of the capture of two electrons by $\alpha$-particles, and the He concentration will increase with cumulative dose from $\alpha$-decay events. The diffusivities of $\mathrm{He}$ in simulated waste glasses are one to two orders of magnitude lower than in silica, alkali silicate, and Pyrex glasses, ${ }^{41}$ and they have been reported to decrease by up to a several orders of magnitude with increasing radiation dose, which suggests trapping of helium at radiationinduced defects. ${ }^{40,52}$ Studies of He diffusion and release in several simulated waste glasses ${ }^{40,52,152,153}$ indicate that most of the He generated at ambient temperature will accumulate in the glass, and only a small fraction of $\mathrm{He}$ will be released. However, the fraction of He released increases with irradiation temperature, and the fraction released at $170{ }^{\circ} \mathrm{C}$ can range from 50 to $100 \% .^{152,153}$ Bubbles (presumed to be $\mathrm{He}$ ) have been observed in simulated waste glasses containing 100 appm of $\mathrm{He}$, introduced by $(n, \alpha)$ reactions during neutron irradiation or by ion implantation, but only after annealing at temperatures between 600 and $700{ }^{\circ} \mathrm{C} .{ }^{52,154}$ When higher $\mathrm{He}$ concentrations (up to $10^{4} \mathrm{appm}$ ) are introduced by $(n, \alpha)$ reactions, bubble formation has been observed at lower temperatures $\left(<100\right.$ to $\left.230{ }^{\circ} \mathrm{C}\right) .{ }^{148,154}$ Bubbles have also been observed in a glass containing both ${ }^{238} \mathrm{Pu}$ and ${ }^{244} \mathrm{Cm}$ after $8 \times 10^{18} \alpha$-decays $/ g$ at ambient temperature, ${ }^{145}$ and, as noted above, the integrated volume of the bubbles correlated with the measured volume change. The exact nature of the bubbles observed has not determined in any of these studies, but are presumed to be $\mathrm{He}$ or $\mathrm{He} / \mathrm{O}_{2}$.

\section{Microstructural changes}

Phase separation has been induced in simulated waste glasses by electron irradiation. ${ }^{132,133,155}$ Radiationinduced amorphization of crystalline phases in a ${ }^{244} \mathrm{Cm}$ doped simulated waste glass has been observed, and the volume expansion associated with this transformation produced significant microcracking. ${ }^{25,156}$ As noted above, $\alpha$-decay ${ }^{145}$ and neutron irradiations to induce $(n, \alpha)$ reactions ${ }^{148,154}$ in waste glasses can result in the formation of bubbles.

In 1976, Hall and co-workers ${ }^{152}$ were the first to report the formation of bubbles, assumed to contain $\mathrm{O}_{2}$, in simulated nuclear waste glasses irradiated with electrons in a high voltage electron microscope (HVEM) at $200{ }^{\circ} \mathrm{C}$ to high doses $\left(10^{10}\right.$ to $\left.10^{11} \mathrm{~Gy}\right)$ in experiments to simulate the effects of $\beta$-irradiation. Since then, electron-beam-induced bubble formation has been observed in a wide variety of glasses..$^{85,132-135,149,157-160}$ The presence of a gas phase in the bubbles was confirmed in the studies of Hall et al. ${ }^{152}$ and Heuer et al. ${ }^{134}$ Ionbeam irradiation ${ }^{124,158,159}$ and $\gamma$-irradiation ${ }^{155,158-160}$ also have been reported to produce bubbles in several simulated waste glasses, as illustrated in Fig. 11. However, $\gamma$-irradiation of one of these same glasses in another study $^{161,162}$ did not produce bubbles, even at an order of magnitude higher dose. This has raised questions regarding whether or not the bubble formation in $\gamma$-irradiated glasses reported by others ${ }^{155,158-160}$ may be an artifact of sample preparation or the electron-beam irradiation during examination using electron microscopy. In this regard, it is important to note that there is a characteristic difference in the bubble sizes and distribution found in $\gamma$-irradiated glasses as compared to electronirradiated glasses. ${ }^{155,158}$ Gamma irradiation leads to more uniform bubble sizes and distributions over a large area (i.e., the whole sample or at least the area that is transparent to electrons in the microscope), as well as bubbles in very thin regions as observed by electron microscopy. Electron irradiation, on the other hand, produces a nonuniform distribution of bubble density and bubble sizes only in a focused beam; bubbles cannot be produced in very thin regions by electron irradiation alone. Another point is that bubbles are observed in a $\gamma$-irradiated glass by electron microscopy at temperatures where bubbles are difficult, if not impossible, to form under intense electron irradiation. ${ }^{155,158}$ Consequently, if bubbles do not form directly under the $\gamma$-irradiations, then the glass must be highly damaged in such a way that the bubbles form nearly instantaneously when exposed to an unfocused electron beam.

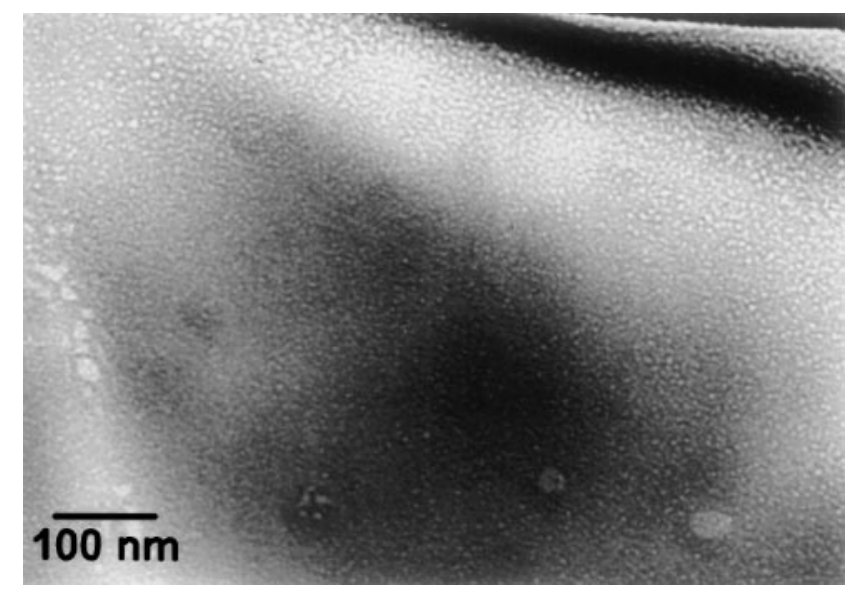

FIG. 11. Bubbles formed in simulated DWPF glass irradiated with $\gamma$-rays to $1.3 \times 10^{7}$ Gy (micrograph courtesy of J.P. Heuer and D. G Howitt, University of California-Davis). 
Quantitative studies have shown that the kinetics of the radiolytic bubble formation process are consistent with the motion of alkali metal cations and not oxygen. ${ }^{133,163}$ The formation of oxygen bubbles is apparently brought about by radiolytic decomposition of the ionic component of the glass, followed by the migration of the cations into the glass and the local precipitation of molecular oxygen. ${ }^{160}$ Irradiation studies ${ }^{158,159}$ utilizing $\gamma$-rays, ion beams, and electron beams at similar temperatures, indicate a significant dose-rate effect for radiolytic bubble formation, as shown in Fig. 12. The reported bubble formation under $\gamma$-irradiation occurs at much lower doses $\left(10^{6}\right.$ to $\left.10^{7} \mathrm{~Gy}\right)$ than for either ion irradiation $\left(10^{7}\right.$ to $\left.10^{10} \mathrm{~Gy}\right)$ or electron irradiations $\left(10^{10}\right.$ to $10^{13} \mathrm{~Gy}$ ). Under electron irradiation, bubble formation occurs over a broad temperature range with a maximum in the rate of formation at $250{ }^{\circ} \mathrm{C} .{ }^{133,159}$ Similar behavior is reported by Manara et al., ${ }^{135}$ who also observed that the peak for bubble formation occurs at a lower temperature $\left(125\right.$ to $150{ }^{\circ} \mathrm{C}$ ) for high $\mathrm{Na}$ glasses (19 and 25 wt. $\left.\% \mathrm{Na}_{2} \mathrm{O}\right)$ than the peak temperature $\left(325^{\circ} \mathrm{C}\right)$ for a low $\mathrm{Na}$ glass $\left(4\right.$ wt. $\left.\% \mathrm{Na}_{2} \mathrm{O}\right)$.

\section{Mechanical properties}

In a recent study of a simulated nuclear waste glass doped with ${ }^{238} \mathrm{Pu}$ and ${ }^{244} \mathrm{Cm},{ }^{164}$ the hardness and Young's modulus decreased exponentially with dose, while the fracture toughness increased exponentially with dose. The maximum values of the relative changes reported for the hardness, Young's modulus, and fracture toughness in these glasses were $-25 \%,-30 \%$, and $+45 \%$, respectively. These changes in fracture toughness strongly correlated to the formation of bubbles which were observed in these glasses. ${ }^{145}$ The bubbles, which can impede crack propagation, anneal with kinetics simi-

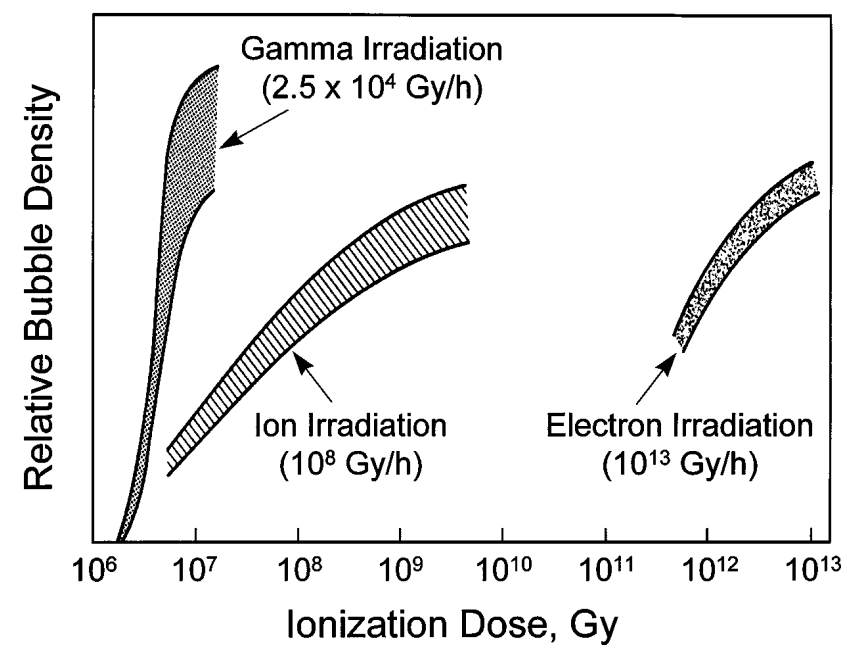

FIG. 12. Dose and dose-rate dependence of radiolytic bubble formation in simulated HLW glasses (adapted from DeNatale and Howitt ${ }^{158}$ and Heuer $^{159}$ ). lar to the recovery of the fracture toughness. Similar decreases in hardness and Young's modulus and increases in fracture toughness have been observed due to $\alpha$-decay damage in three different glasses containing ${ }^{244} \mathrm{Cm} .{ }^{165-167}$ Irradiation-induced decreases in hardness and increases in fracture toughness also have been reported in a number of other studies. ${ }^{168-170}$

\section{Enhanced diffusion}

Yamashita and Matzke ${ }^{171}$ investigated radiation enhancement of $\mathrm{Na}$ diffusion in a simulated waste glass (GP 98/12) under irradiation at relatively low dose rates with $\alpha$-particles emitted from ${ }^{244} \mathrm{Cm}$ and ${ }^{239} \mathrm{Pu}$ sources. (The ${ }^{244} \mathrm{Cm}$ irradiations simulate dose rates for accelerated actinide-doping experiments and the ${ }^{239} \mathrm{Pu}$ irradiations simulate dose rates for actual HLW glasses.) Although $\mathrm{Na}$ depletion is observed in this glass under high dose rate electron irradiation at room temperature, ${ }^{172}$ these investigators found that, within experimental error, there was no evidence for significant radiation-enhanced $\mathrm{Na}$ diffusion in this glass under the more realistic dose-rate conditions. Although the experimental errors are considerable at the low temperature conditions of the study, the results indicate that the radiation-enhanced $\mathrm{Na}$ diffusion is no more than a factor of 2 to 5 at temperatures below $150{ }^{\circ} \mathrm{C}$.

\section{Radionuclide release}

Radiation affects the release rate of radionuclides from waste glasses by increasing the surface area for radionuclide release (microfracturing) and by changing the dissolution rate of the glass. The extent of the radiation-induced microfracturing will depend on differential volume changes, development of microstructures, and mechanical properties. The dissolution rate of nuclear waste glasses may be affected by the radiationinduced changes in chemistry, microstructure, network bonding, and along $\alpha$-recoil tracks. As noted in several reviews, ${ }^{25-27,29-32,173}$ almost all data concerning the effects of $\alpha$-decay on dissolution (leach) rates of waste glasses were determined prior to 1982 in short-term tests based solely on weight loss. The data obtained from these tests indicate no more than a factor of three increase in the short-term dissolution rates as a result of radiation effects from $\alpha$-decay. Ion-irradiation ${ }^{149,174,175}$ and neutron-irradiation ${ }^{176}$ studies of several HLW glasses have shown irradiation-enhanced dissolution rates of up to a factor of four. Ion irradiation, however, is known to introduce compositional variations, ${ }^{51}$ which affect the interpretation of the results. Gamma-irradiation of several HLW glasses up to $10^{9}$ Gy also leads to increases in dissolution rates of up to a factor of four. ${ }^{44,177,178}$ It is now well established that the short-term tests based on weight loss in these studies can underestimate 
the radiation-induced increases in dissolution rate by a factor of three to four due to precipitation of alteration phases on the surface of the glass ${ }^{29,179}$; consequently, based on the limited data and understanding available, it has been suggested by Weber ${ }^{29,30}$ that radiation-induced changes in HLW glass structure are not expected to increase the leach rate by more than a factor of 10 , provided there are no radiation-induced phase separations or transformations. This assessment is supported by a study ${ }^{49}$ of a seventeen-year-old borosilicate glass containing $4 \mathrm{wt}$. $\% \mathrm{ThO}_{2}$, where the Th daughter product release rate was increased 15 to $45 \%$ due to incongruent dissolution along the recoil tracks produced by the $\alpha$-recoil nucleus. For the $\alpha$-decay damaged glass, the initial ${ }^{228} \mathrm{Th}$ leach rate was enhanced relative to the initial ${ }^{232} \mathrm{Th}$ leach rate due to the selective removal of radiogenic ${ }^{228} \mathrm{Th}$ nuclides from ${ }^{228} \mathrm{Ra}$ recoil tracks $\left({ }^{232} \mathrm{Th}\right.$ decays to ${ }^{228} \mathrm{Ra}$ by $\alpha$-decay and the ${ }^{228} \mathrm{Ra} \beta$-decays to ${ }^{228} \mathrm{Th}$ ). Heating at $650{ }^{\circ} \mathrm{C}$ prior to leaching eliminates the ${ }^{228} \mathrm{Th} /{ }^{232} \mathrm{Th}$ fractionation. Thus, it is evident that the $\alpha$-recoil tracks in glass represent localized regions of severely damaged, chemically reactive, material. Similar phenomena have been well described in crystalline materials. ${ }^{50,180,181}$ Another recent study, ${ }^{166}$ however, of HLW glasses containing ${ }^{244} \mathrm{Cm}$ has shown that radiation damage from $\alpha$-decay does not significantly increase the bulk leach rate when measured by solution analysis, as recommended by a previous workshop. ${ }^{23}$ The effects of radiation-induced structural changes on glass dissolution range from insignificant to significant, depending on glass composition and what is actually measured. As a result, this subject remains highly controversial and in need of systematic investigation.

\section{FUNDAMENTAL SCIENTIFIC ISSUES}

Glass waste forms for the DWPF, WVDP, Hanford, and weapons plutonium applications represent complex multicomponent systems. Though the composition ranges of borosilicate glass for DWPF and WVDP are well established, possible glass compositions for Hanford HLW and weapons plutonium immobilization have not yet been determined, and several competing glass and crystalline formulations are under consideration. Even for DWPF, the waste vitrification campaign will proceed for over 20 years, the glass canisters must be stored until a repository is opened, and the repository will probably remain open for less than 100 years, at which time it will be sealed. Thus, there is time to identify and address fundamental scientific issues, in particular those related to the effect of radiation on waste form properties, which may have a bearing on cost, optimization of processing technologies, the integrity of the HLW glass canisters until the repository is sealed, and long-term performance.

In the following discussion, critical areas are outlined for which the panel determined that there is an absence of a systematic understanding of radiation effects on waste form glasses. The phenomenological systematics require that the knowledge of simple glassradiation interactions be extended to glasses of complex compositions. The scientific basis for the extrapolation of radiation effects data and models based on short-term experimental studies (actinide-doping and ion-beam irradiations) to the longer time periods relevant to nuclear waste disposal is reviewed.

\section{A. Glass structure and energetics}

Nuclear waste glasses are structurally complex. A borosilicate glass contains network formers $(\mathrm{Si}, \mathrm{Al}, \mathrm{B})$ and network modifiers (alkalis and alkaline earths), as well as large-size, high-valence-state cations (lanthanides and actinides) that occupy irregular sites of large coordination number and that generally are not good glass formers. ${ }^{182}$ The oxidation states of ions such as $\mathrm{Fe}, \mathrm{Mn}$, $\mathrm{Ce}, \mathrm{U}$, and $\mathrm{Pu}$ are variable. The ratio of network formers to network modifiers is such that the ratio of bridging to nonbridging oxygens varies. Boron can exist in both tetrahedral and trigonal coordination. Structural studies on simpler model glasses have produced a considerable knowledge of short-range order and local coordination, but few structural studies have been completed on simulated or actual nuclear waste glasses themselves, either before or after the accumulation of radiation damage. As noted above, there is a need for an improved method to describe glass structure and for more structural data on all potential HLW glass compositions than currently exists.

What is clear is that such HLW melts and glasses are not very far from regions of glass-glass immiscibility inherent to borosilicate glasses and to high field strength ionic glasses. ${ }^{183}$ For $\mathrm{La}_{2} \mathrm{O}_{3}$ dissolved into potassium silicate glasses, Ellison and Navrotsky ${ }^{182}$ have argued that the enthalpy of mixing suggests extensive clustering or incipient phase separation. Radiation-induced changes in glass energetics enhance heterogeneity and may trigger phase separation.

Another possible effect of radiation damage in HLW glasses is mixing. Because atoms are displaced and bonds broken, a more homogeneous structure may result. Some of the volume changes seen in actual waste glasses may reflect relaxation to a more stable structure. ${ }^{150}$ A study of the glass transition in $\mathrm{As}_{2} \mathrm{Se}_{3}$ suggests that radiation damage allows the glass to relax to a lower fictive temperature and an energetically more stable state. ${ }^{184}$ Thus it is not clear under what conditions radiation raises the free energy of a glass and in what circumstances it allows the glass to find a state of lower free energy. The possible kinetic enhancement of crystallization and stable phase separation by such bond breaking may be another manifestation of the latter case. Understanding the direction in which radiation-solid interactions drive 
waste glass energetics, toward chemical equilibrium or away from it, is critical to understanding the long-term behavior and durability. Another possibility is that, under steady state irradiation, the actual equilibrium state may be altered, with different phases being stabilized. The effects of radiation on glass energetics require considerable additional study. Because of the possible competing mechanisms of defect production and recovery, the effects of temperature are likely to be complex.

When either quartz or silica glass is neutron irradiated, its energy increases. Quartz expands under irradiation, while silica glass compacts. Both crystalline and glassy silica appear to approach a similar (or perhaps identical) final density state or plateau characterized by $3 \%$ densification relative to silica glass and $18 \mathrm{~kJ} / \mathrm{mol}$ excess enthalpy relative to quartz. ${ }^{185}$ Spectroscopically and energetically, these irradiated glasses are different from fused silica and from pressure-densified silica of comparable density. ${ }^{185-188}$ Does damage by other forms of radiation follow similar trends? If radionuclides in nuclear glasses are partitioned into different glass phases, does the radiation ( $\alpha$-particles, $\alpha$-recoils, $\beta$-particles, $\gamma$-rays) result in similar or different changes in physical and chemical properties? Answers to these questions (and those posed below) will require a systematic understanding of the structure, phase equilibria, and energetics of both undamaged and radiation-damaged glasses that range in composition from simple to complex. Obtaining this understanding will require the application of modern characterization techniques to studies of both nonradioactive and radioactive glasses. These techniques include, but are not limited to, electron-spin resonance, nuclear magnetic resonance, Raman spectroscopy, synchrotron radiation spectroscopies, neutron and x-ray diffraction, analytical electron microscopy, and calorimetry.

\section{B. Ionization versus ballistic effects}

\section{Electron- and X-irradiations}

$E^{\prime}$-centers in fused silica glass are associated with ESR (electron spin resonance)-active oxygen vacancies. ${ }^{189}$ An early attempt was made to measure the displacement energy required to form the O-vacancy in fused silica by monitoring the associated optical absorption $(215 \mathrm{~nm})$ as a function of a given flux of electrons at varying energies $(0.5-2.0 \mathrm{MeV})$ normalized to the absorption at $2.0 \mathrm{MeV} .{ }^{190}$ The concentration of $\mathrm{O}$-vacancies measured in this manner increased with decreasing electron energy and, indeed, corresponded almost entirely to the energy lost by the electrons through ionization processes as they traversed the silica samples. X-ray $(50 \mathrm{kV})$ irradiations for doses matching those of the electron-irradiated samples confirmed that $\mathrm{O}$-vacancies could be produced by purely ionizing irradiation and that the nonsaturating absorption showed that they involved vacancy creation and not simply the filling of existing vacancies by electrons. These results were later confirmed by Pfeffer ${ }^{191}$ in studies on thermal oxides that showed the effects of $\mathrm{H}$ in damage annealing, a factor that was noted in prior work. ${ }^{190}$ Still further conclusive evidence of the dominant role of ionization in producing actual displacements was provided by the work of Tsai and Griscom ${ }^{109}$ who showed that the decay of self-trapped excitons produced by a two-photon process ( $6.4 \mathrm{eV}$ excimer laser photons) alone can cause displacements of $\mathrm{O}$ atoms from the silica network. Similar studies of HLW glasses that employ electrons, x-rays, and $\gamma$-rays are needed to verify whether or not ionization processes are an important mode of radiation damage in these complex HLW glasses, as has been suggested.

\section{Ion-irradiations}

The dominance of ballistic (collisional) processes over electronic processes for producing ion-beam damage in fused silica glasses was established in studies by EerNisse ${ }^{81}$ and by Presby and Brown. ${ }^{82}$ Both of these investigations estimated that ballistic processes are about a factor of 200 more effective in producing damage than electronic processes in silica glass. The experimental approach of EerNisse ${ }^{81}$ (i.e., measuring the cantilever-beam deflections produced by induced surface stress) has been exploited for determining the dominant mechanism for producing defects under ion irradiation in a variety of glass systems. The stress data (volume changes) in fused silica irradiated with incident ions of varying mass were found to scale with ballistic energy deposition. ${ }^{81,89}$ In simple alkali $(\mathrm{Na}, \mathrm{K})$ borosilicates, Pyrex (commercial borosilicate), and soda-lime glass (microscope slide), the stress values scale with electronic energy deposition..$^{89,120,137,139}$ For the alkali-borosilicate nuclear waste glasses, PNL 76-68 and DWPF, the damage from ion irradiation $(\mathrm{He}, \mathrm{Xe}, \mathrm{Pb})$ also scales with energy deposition in electronic processes. ${ }^{89}$ For $\alpha$-decay, this means that the $5 \mathrm{MeV} \alpha$-particle, which loses most of its energy through ionization events, may be of greater importance rather than the $100 \mathrm{keV}$ heavy recoil in causing permanent radiation damage in HLW glass compositions. It should be noted that the saturation values for stress in the implanted nuclear waste glasses occur for deposited energies equivalent to $10^{8}-10^{9} \mathrm{~Gy}$. Although ionization appears to be the dominant radiation damage process for borosilicate waste glasses under high-dose-rate electron and ion bombardment, this must be established for the much lower dose rates that actual glasses will experience from $\alpha$ and $\beta$ decay.

\section{Relaxation processes and diffusion \\ 1. Relaxation processes}

The subject of relaxation phenomena in glass is a complex one, and the effects of radiation must further 
complicate the process. At the glass transition temperature, $T_{g}$, the fundamental enthalpy relaxation time is about $100 \mathrm{~s}$. Above $T_{g}$, radiation should have little effect on the properties of a glass because of the short time scale $(<100 \mathrm{~s})$ on which radiation damage is relaxed. Near $T_{g}$, the stabilization of the glass structure will greatly reduce the mobility of any species that are not too decoupled from the glass structure; this is presumably related to the rapid decreasing probability of percolation paths for such species as the glass structure compacts. The overall structure of the glass becomes relatively fixed at temperatures much below $T_{g}$; however, certain modes of motion remain active. These are modes that have been split off (decoupled) from the principal structural relaxation modes during cooling within the liquid state and continue to be active in the glass. The best studied of such modes are those due to small, lowcharged ions such as $\mathrm{Li}^{+}, \mathrm{Ag}^{+}$, and (in fluoride glasses) $\mathrm{F}^{-}$, which can move via low activation energy pathways within the liquid and, at lower temperatures, within the glass structure. Most data come from conductivity studies, though NMR and diffusivity have also been studied.

Similar decoupling processes must occur for the mobility of network modifiers, especially the alkalis, and for the gas atoms or molecules (i.e., $\mathrm{He}$ and $\mathrm{O}_{2}$ ) that are generated. The decoupled motion of these species should persist to temperatures much lower than $T_{g}$. Understanding the motion of alkali ions and gas species in relation to the structural relaxation of the glass is especially lacking. Radiation may affect alkali mobility, as discussed below, and this should be studied by diffusion, electrical conductivity, and NMR measurements of original and irradiated glasses. The understanding of transport properties in a glass under a strong radiation field should be investigated using both computer simulations and experimental techniques. There are no studies of these types of decoupling processes over long periods of time.

\section{Diffusion}

Both ionizing and displacive radiation can enhance the diffusion of ionic and gaseous species in the glass. This is because "bottlenecks" in the glass structure can be temporarily opened or reorganized either by local ionization (modifying Coulombic barriers) or by displacement of blocking species - or simply by short-term local heating due to nearby radiation tracks. Radiationinduced expansion of the glass structure may also lead to enhanced diffusion of some species. In some glasses, however, radiation can cause annealing that would normally lead to decreased mobilities for small ions and gaseous species. $\mathrm{As}_{2} \mathrm{Se}_{3}$, for instance, can be annealed to a lower enthalpy state under neutron radiation below $T_{g}$ than could be obtained by normal thermal annealing. ${ }^{184}$ Which conditions will apply to the glass compositions under consideration for radioactive waste disposal can be determined only by experiment.

Marked modification of the near-surface alkali concentrations in electron-irradiated glasses is well known (e.g., it is a disturbing feature of Auger electron spectroscopy). ${ }^{192-194}$ For these effects, the changes in alkali compositional depth profiles appear to be governed by ordinary and electric-field assisted diffusion where the electric field is a function of the irradiation depth both for electron- and proton-irradiated glasses. ${ }^{194,195}$ The surface depletion of alkali results in an accumulation of alkali at a depth roughly corresponding to the electron range. ${ }^{122,123}$ For $\mathrm{MeV}$ proton-irradiation, the alkali movement is from the irradiated depth toward the surface, resulting in an abnormal surface concentration of alkalis. The early stages of nuclear waste glass dissolution involve ion exchange reactions (e.g., $\mathrm{Na} \leftrightarrow$ $\mathrm{H}_{3} \mathrm{O}$ ), thus near surface increases in the alkali content may affect the dissolution rate.

For heavy-ion irradiations, alkali ions are removed from depths corresponding to the heavy-ion range, and for continued irradiation to high fluences, the entire nearsurface region can be depleted of alkali ions to depths exceeding the ion range. ${ }^{121}$ These heavy-ion effects have been interpreted using a phenomenological model based on radiation-enhanced migration over the incident ion range and preferential sputtering of the alkali at the surface.

Almost all the studies to date of radiation-enhanced alkali diffusion have involved high dose rate irradiations with electrons or ions. Actual nuclear waste glasses will be exposed to much lower radiation dose rates. Only in the study of Yamashita and Matzke ${ }^{171}$ has the radiationenhanced diffusion of $\mathrm{Na}$ been studied under more realistic dose rates with $\alpha$-particles emitted from ${ }^{244} \mathrm{Cm}$ and ${ }^{239} \mathrm{Pu}$ sources. In this case, Na depletion, which is observed in this glass under electron irradiation, ${ }^{172}$ is not observed under the much lower dose-rate conditions, and the enhancement of $\mathrm{Na}$ diffusion is estimated to be no more than a factor of 2 to 5 at temperatures below $150{ }^{\circ} \mathrm{C}$. Although similar studies are needed for other glass compositions, this work highlights the need for studies at realistic dose rates combined with a thorough understanding of dose rate effects on various processes.

\section{Temperature and dose rate effects}

Accelerated irradiation methods must be used to achieve repository relevant doses in laboratory time frames. These methods include incorporation of actinides, $\gamma$-irradiation, electron irradiation, and ion irradiation. At the high dose rates employed under electron and ion irradiations, the effects of irradiation are observed at much higher temperatures because the high damage rates overwhelm the thermal recovery processes. This 
effect is mitigated to some extent by the irradiationassisted recovery processes that are also observed under electron and ion irradiations. One of the key questions is: Is there a dose rate below which the effects of dose rate are negligible? A systematic, integrated understanding of dose-rate effects is required for the extrapolation of data obtained using accelerated methods under high dose rates to the actual long-term, low dose rate behavior of nuclear waste glasses.

A detailed study ${ }^{196}$ of radiation-induced amorphization in zircon showed an excellent correlation between heavy-ion ( $\mathrm{Kr}$ and $\mathrm{Xe}$ ) irradiations at $25{ }^{\circ} \mathrm{C}$ and $\alpha$-decay effects at ambient temperature in ${ }^{238} \mathrm{Pu}$ containing synthetic zircon (6.5 years old) and U/Thbearing natural zircons (570 million years old), a difference in dose rates of over $10^{13}$. This correlation is observed in the temperature regime where amorphization of zircon does not exhibit significant temperature dependence, which suggests that dose-rate effects may not be important at temperatures where the damage is temperature independent (i.e., recovery processes are negligible). Such correlations have not yet been shown in irradiation damage studies of glasses, and temperatureindependent regimes for irradiation damage in HLW glasses have not been identified. If radiation effects in HLW glasses exhibit some temperature dependence at the anticipated storage temperatures, then dose-rate effects will generally be important.

\section{E. Radiation-induced transformations}

Possible radiation-induced phase transformations include phase separation, devitrification, and amorphization of crystalline phase impurities present in the glass or formed during cooling.

\section{Phase separation}

Phase separation (immiscibility) occurs over a limited temperature-composition domain. The curve (surface) that delimits the one phase (homogeneous) from the two phase region is termed the binodal. The temperature associated with the highest binodal temperature is termed the consolute (or critical) temperature, and is denoted by $T_{c}$. Above $T_{c}$, the single phase liquid is the equilibrium state for all compositions. If $T_{c}$ occurs above the liquidus temperature $\left(T_{l}\right)$, then the portion of the immiscibility region that occurs above $T_{l}$ is stable, and the equilibrium state corresponds to the two liquid phase region. The portion of the immiscibility domain that falls below $T_{l}$ is metastable, since the two liquids do not correspond to the equilibrium state. Hence, in regions of metastable immiscibility, further phase transformations are possible. Stable immiscibility usually is produced quite rapidly; thus, it is exceedingly difficult to avoid (even by rapid quenching methods).
Phase separation is of importance since it can be deleterious to the chemical durability of the glass. Depending upon chemical composition, phase separation can produce two types of morphologies: (i) an interconnected structure, or (ii) a droplet structure in a continuous matrix. ${ }^{197,198}$ If immiscibility occurs and a structure of type (i) is formed, or a structure of type (ii) results in which the droplets correspond to the more durable phase, then phase separation will result in a degradation of the chemical durability of the glass.

Since many nuclear waste glasses are complex sodium borosilicate (NBS) based glasses, it is of interest to briefly review the phase separation behavior of NBS glass. The NBS system exhibits a broad region (of partially stable) immiscibility extending up to about 16 mole \% soda and for nearly all $\mathrm{SiO}_{2}$ compositions in excess of 20 mole \%. ${ }^{199,200}$ Phase equilibrium studies have indicated that typically one phase is an extremely silica poor phase which possesses inferior chemical durability, and the other is a chemically durable phase consisting nearly of pure vitreous silica. Thus, as discussed above, there exists a wide compositional range for which NBS glass durability will be degraded by immiscibility. This undesirable feature is further exacerbated by the fact that most fission products tend to partition into the less durable glassy phase.

Thus, one important scientific issue pertains to the influence of glass composition upon immiscibility behavior. Although considerable work has been performed upon the influence of divalent and trivalent ions upon phase separation in alkali borosilicate glass systems, much less is known concerning the effects of cations of valence four or greater on phase separation in such systems. A second issue relates to the lack of information regarding the influence of melting history upon the extent and nature of phase separation in these glasses. Melting time, temperature, redox conditions, and cooling rates are several specific factors which strongly influence immiscibility behavior, especially if the composition contains cations which can occur in more than one valence state (e.g., Fe, Pu, U). The valence states and the effects of irradiation on the valence states can be studied by electron spin resonance techniques. For example, if the total iron in a glass sample should be known, an ESR determination of the $\mathrm{Fe}^{3+}$ content can be sufficient to determine the $\mathrm{Fe}^{3+} / \mathrm{Fe}^{2+}$ redox ratio. ${ }^{201}$

An important consideration is the influence of the radiation field and the radiation products upon phase separation. There are scant data detailing radiation-induced changes in composition or compositional redistribution, because few of the requisite studies appear to have been done. Radiolysis in the TEM has been observed to induce phase separation (possibly spinodally) in a PNL 76-68 waste glass into silica-rich and heavy-metal-rich components, ${ }^{132}$ and also to sharpen initially diffuse phase 
boundaries in a $\mathrm{K}_{2} \mathrm{O}-\mathrm{Al}_{2} \mathrm{O}_{3}-\mathrm{CaO}-\mathrm{SiO}_{2}$ glass derived from earlier spinodal decomposition. ${ }^{202}$ Because phase separation is known to occur thermally in both these glasses, it is likely that radiation-enhanced diffusion simply accelerates the process. The potential for irradiation to induce phase separation more generally in otherwise stable glass compositions is presently unknown; however, implantation of $2 \mathrm{PbO}-\mathrm{P}_{2} \mathrm{O}_{5}$ glass with $\mathrm{P}^{+}$ions has been shown to result in phase separation of $\mathrm{Pb}$-rich regions. $^{203}$

Even if the as-prepared glass does not exhibit phase separation, radiation effects could induce immiscibility, especially if the glass composition lies in the vicinity of a region of immiscibility. Several possible conditions could produce this effect. First, collision cascades could produce high energy states characterized by an altered number of nonbridging oxygens and a change in average boron coordination number. This state could be metastable with respect to a two-phase (nonequilibrium) state, and phase separation could ensue abetted by radiation-enhanced diffusion. A second possibility is that radiation-induced heating could cause selective volatilization, thus altering the glass composition. If the as-prepared composition is near a region of immiscibility, then this composition shift could produce a glass of composition within the binodal. Furthermore, the elevated temperature would enhance the phase separation kinetics. Finally, one must consider the influence of the radiation products. Since the radioactive decay process alters the glass composition, one must consider the immiscibility behavior of systems which contain new chemical components. The above effects must not only be examined individually, but also the possibility of these influences acting in a synergistic fashion must be studied.

The discussion given above suggests the need for experimental investigation of the thermodynamic and kinetic aspects of phase separation in unirradiated and irradiated glasses. One should investigate three types of glass with compositions of increasing complexity. The simplest glass should be a binary glass composition that exhibits phase separation, and whose thermodynamic and phase separation features are well characterized. The influence of radiation upon a composition that falls in the vicinity, but outside, of the binodal should be investigated. The composition of intermediate complexity should be a 4 or 5 component NBS based composition which contains at least one cation which can assume two (or more) valence states. For this glass, one should investigate the influence of melting conditions and compositional excursions on immiscibility behavior, as well as the influence of radiation effects, especially ionization effects. The most complex glass composition should be a multicomponent prototype waste glass composition. This composition should be examined in a manner that would be dependent upon the information gained from the studies of glasses of intermediate complexity. Phase separation can be monitored via the use of electron microscopy (TEM and SEM), selective phase etching, and small angle $\mathrm{x}$-ray scattering (SAXS). For the most reliable experimental study, one should use a combination of these techniques.

\section{Devitrification}

The formation of crystalline phases (devitrification) during cooling of the waste glass from the melt temperature is generally undesirable, as it often leads to decreased chemical durability. ${ }^{204}$ Waste glass compositions are generally optimized to minimize the formation of such crystals. The center line cooling rate of the glass is on the order of $10{ }^{\circ} \mathrm{C} / \mathrm{h}$ until the temperature reaches 200 to $250{ }^{\circ} \mathrm{C}$, at which time self-heating from radionuclide decay slows the cooling rate. The temperature of the glass will generally fall to below $150{ }^{\circ} \mathrm{C}$ after several hundred years. Devitrification in waste glass compositions is not observed in laboratory studies below $525{ }^{\circ} \mathrm{C}^{204}$; consequently, devitrification is generally assumed not to occur once the glass is placed in storage. Radiation-induced devitrification has not been observed in any borosilicate glasses studied to date. Near the glass transition temperature, radiation-induced devitrification may be more probable as radiation interaction processes provide additional energy to overcome any activation barrier. However, at repository-relevant storage temperatures, radiation-induced devitrification is less likely. The only exception to this would be the precipitation of alkali metal crystals, such as $\mathrm{Na}$, due to radiolytic decomposition and diffusion.

\section{Amorphization of crystalline phases}

High-level waste glasses being produced at DWPF and WVDP will not contain a significant amount of secondary crystalline phases according to current acceptance criteria. Such restrictions on secondary crystalline phase formation could be relaxed for glasses proposed for immobilizing HLW at Hanford and the Idaho National Engineering Laboratory or for glasses proposed for plutonium disposition. If such crystalline phases are present and radionuclides partition preferentially into these phases, then radiation effects in the crystalline phases will be an issue. Alpha-decay induced amorphization of such crystalline phases has been previously observed $^{25,156}$ and is accompanied by volume changes that can exceed $15 \%,{ }^{32}$ which can lead to microcracking. There are a significant amount of data and understanding of amorphization in crystalline phases, as this is an active area of research, ${ }^{32,205}$ that can be used to predict the effects of radiation on such phases. 


\section{F. Volume changes}

At low to intermediate dose levels, there is a significant amount of data on radiation-induced volume changes in glasses ranging from fused silica to complex borosilicate waste glasses, as discussed above. The volume changes in bulk-irradiated specimens (actinidecontaining, $\gamma$-irradiated, or neutron-irradiated) can be determined easily from density changes. For electron or ion irradiations, the cantilever-beam technique ${ }^{81}$ has been used very successfully. The radiation-induced volume changes are the result of the accumulation of point defects, network rearrangements and rebonding, and the development of microstructural defects such as gas bubbles and voids. At relatively low doses, the accumulation of point defects in both simple and complex glasses, as observed by ESR, spectroscopic techniques, and stored energy, reaches steady state defect concentrations without significant volume changes (Figs. 7 and 10). Following the saturation of the simple defect concentrations, the compaction or expansion that is measured is generally within the range of $\pm 1.2 \%$. Whether compaction or expansion occurs at low to intermediate dose levels may be largely dependent on composition, processing conditions, and whether or not phase separation occurs. These changes are probably the results of network rearrangements and rebonding, as suggested by Devine. ${ }^{60}$ They also may be associated with the radiation-enhanced equilibration of the glass to its ideal density for the given composition. ${ }^{150}$ Few data are available on the effects of temperature on volume changes. A more fundamental understanding of the compaction or expansion that occurs at these dose levels is desirable in order to model and predict behavior at larger doses, such as expected for Pu disposition. Significantly larger compaction at higher doses is probably not feasible, unless there is radiation-induced devitrification. Volume expansion of the compacted or expanded structures, however, can result at higher doses from the formation of gas bubbles or voids as a result of the He that is generated from $\alpha$-decay and/or the radiolytically generated $\mathrm{O}_{2}$. More experimental research is needed on the volume changes at high $\alpha$-decay doses as a function of temperature in glasses for $\mathrm{Pu}$ and other actinide disposition, and temperature dependent models are needed to describe the network rearrangements and formation of bubbles or voids.

\section{G. Gas accumulation and bubble or void formation}

The oxygen vacancy centers, nonbridging oxygens and neutral alkali atoms, together with $\mathrm{He}$ atoms (generated from $\alpha$-decay) and possibly molecular oxygen from disproportionation, comprise the observable primary defect spectrum of alkali silicate-based glasses.
Other point defects, which are not observable spectroscopically, could be generated by $\beta-\gamma$ radiolysis and transiently in the displacement cascades accompanying $\alpha$-recoil. These defects and gas atoms/molecules can diffuse, interact, and aggregate to become trapped at defects or form bubbles/voids. Existing models ${ }^{206}$ developed for bubble growth in metals under irradiation can probably be modified to model the phenomena in glasses.

As noted above, radiation damage in alkali silicates may produce clusters of alkali atoms and evolution of oxygen gas as endproducts of a complex series of defects involving peroxide and superoxide ions. In addition to potential problems of gas bubble formation, such decomposition can create compositional heterogeneity in the glass. An important issue is whether similar processes occur in complex waste glasses and do they lead to the formation of bubbles or voids? The application of electron spin resonance, Raman spectroscopy, and other advanced characterization techniques to radiation damage studies of complex waste glasses will assist in answering these questions.

There is no debate over whether or not bubbles form under electron and ion irradiation; the only controversies are whether or not bubbles actually form under $\gamma$-irradiation and whether or not the electron- and ionirradiation results are relevant. Surprisingly, there has been no research effort to resolve these controversies, which have lingered for nearly a decade, despite the fact that careful experimentation could probably lead to resolution. There are three important points from the $\gamma$-irradiation studies of bubble formation that are important to note. First, the minimum electron fluence (around $5 \times 10^{20} \mathrm{e} / \mathrm{m}^{2}$ ) to image $5 \mathrm{~nm}$ bubbles in a TEM amounts to an ionization dose of about $10^{7} \mathrm{~Gy},{ }^{207}$ or about 1000 times less than the electron dose to nucleate bubbles; thus, it appears that electrons can indeed be used to monitor bubbles formed by $\gamma$-irradiation, though carefully controlled confirmatory experiments must be performed. Second, the uniform density of smaller bubbles produced in the $\gamma$-irradiated glasses is significantly different than the highly localized larger bubbles produced in a focused electron beam. It is possible that $\gamma$ irradiation causes the nucleation of small bubbles more effectively, perhaps because of the longer irradiation time (five orders of magnitude smaller dose rate). Third, in the limited studies to date, bubble formation under $\gamma$-irradiation generally occurs at temperatures where bubbles are difficult to form by electron irradiation, which is consistent with expected dose-rate behavior. Consequently, in the absence of scientific understanding and based on data in the literature, it seems very probable that bubble formation could occur in HLW glasses as a result of ionization damage from $\beta-\gamma$ radiation. The issue of whether or not oxygen bubbles form in HLW glasses under actual storage conditions must be resolved 
scientifically; otherwise, in any performance assessment, one must assume some finite probability for bubble formation and potentially large volume changes, perhaps as high as the $50 \%$ volume change ${ }^{85,135,149}$ observed under electron irradiation. A detailed investigation of glasses irradiated with $\gamma$-rays over a broad range of temperatures is needed to resolve this issue.

Alkali, particularly $\mathrm{Na}$, mobility and depletion has been linked to bubble formation. Due to the high mobility of alkali, any chemical potential gradient will cause some alkali depletion. Consequently, the effects of thermal, electric field, and stress gradients on bubble formation should be investigated as a function of temperature in an ionizing radiation field.

The relevance of the electron- and ion-beam results is more difficult to address. The ion-beam results are certainly relevant to $\alpha$-particles and suggest that the $\alpha$-particles will generate radiolytic oxygen, in addition to helium, which under the appropriate temperature and dose-rate conditions can lead to bubble or void formation. Similar studies need to be performed over a temperature range that encompasses the actual storage temperatures. The electron-beam results do provide a means to evaluate whether or not bubbles can form under the TEM conditions used to examine $\gamma$-irradiated samples. Electron irradiations also can be used to rapidly determine any temperature dependence; however, such studies should include a careful investigations of doserate effects.

Bubbles must be distinguished from voids and voids that contain only a few gas molecules. Gas molecules $\left(\mathrm{He}\right.$ and $\mathrm{O}_{2}$ ) accumulating interstitially soon generate physically unrealistic strains, and it is more likely that oxygen molecules from radiolytic decomposition accumulate in voids or cages effected by network structural rearrangements or alkali loss. In alkali halides, for example, excess halogen molecules are accommodated in cation-anion vacancy pairs, whose aggregation in turn generates voids filled with halogen. ${ }^{208}$ The difference in specific volumes of vacancy pairs and molecules renders $\mathrm{Cl}_{2}$ bubbles in $\mathrm{NaCl}$ or $\mathrm{KCl}$ under very high pressure (probably as highly strained fluid inclusions), but iodine in KI in a strain-free state. ${ }^{209}$ Inclusions of different charge density are most efficiently imaged in TEM by Fresnel (out-of-focus) contrast independent of matrix crystallinity, and strained inclusions in crystalline matrices by Bragg (diffraction) contrast. In aperiodic glasses, the latter contrast mode is not available to image strain fields and thus distinguish empty or partially filled cavities from high-pressure bubbles. The use of small-angle neutron and $\mathrm{x}$-ray scattering can be used to measure microstructural changes, such as voids and bubbles, and with careful experimental design, it may be possible to distinguish gas-filled bubbles from voids.

\section{H. Chemical durability}

Radiation can affect the release rate of radionuclides from waste glasses by increasing the surface area for radionuclide release (microfracturing) and by changing the dissolution rate of the glass. The extent of the radiation-induced microfracturing will depend on differential volume changes, microstructure, and mechanical properties. Presently, there are insufficient data and understanding available to predict the extent of radiationinduced microfracturing in HLW glasses, except to note that it can be expected to occur, especially as a result of radiation-induced differential expansion of phaseseparated regions or any crystalline phases that may be present in the glass.

The actual dissolution rate of nuclear waste glasses may be affected by the radiation-induced changes in chemistry, microstructure, network bonding, and along radiation-damage tracks. As noted above, the changes in leach rates due to radiation-induced structural changes range from insignificant to significant, and the effects of radiation on radionuclide release are highly controversial. This will be resolved only by detailed studies of the changes in structure and leaching studies that combine elemental analysis and isotopic analysis of nuclides in solution. It is clearly important to understand the relationship between the radiationinduced structural changes and enhanced dissolution. The actual radionuclide release rate will depend on geochemical conditions (e.g., presence or absence of silica-saturated solutions) and glass-canister interactions, ${ }^{6}$ which need to be studied. Similarly, the effects of elevated storage temperatures on the radiationenhanced dissolution cannot be predicted at this time and should be investigated. Higher temperatures could promote recovery processes. However, bubble formation and phase separation could be enhanced at elevated temperatures, and the effects of these structural changes on dissolution rates need to be understood. It is equally important to perform studies at the much higher cumulative doses that will be experienced by glasses for $\mathrm{Pu}$ and other actinide disposition. In this regard, the release rate of alpha-decay daughter products (e.g., ${ }^{235} \mathrm{U}$ ) can be expected to be higher than that of the parent nuclide $\left({ }^{239} \mathrm{Pu}\right)$ due to the damage track formed by the recoiling daughter. Although this has been observed in several glass and crystalline systems, it should be confirmed for nuclear waste glass compositions. Understanding this behavior would benefit greatly by detailed characterization of the local structure around the actinides using techniques such as extended $\mathrm{x}$-ray absorption fine structure (EXAFS), site-selective laser spectroscopies, and anomalous x-ray scattering (AXS). In general, AXS will be more powerful than EXAFS for measurements of this type; it provides reliable 
quantitative information, and probes the structure associated with second and higher neighbors that is almost impossible to obtain on disordered materials with EXAFS.

\section{Theory and computer simulations}

Theory and computer simulation or modeling can provide an explanation or interpretation of macroscopic processes in terms of the underlying atomistic mechanisms. The noncrystalline nature of glass, coupled with the inherent chemical complexity of the waste glasses, suggests that theory and simulation are essential to complement the range of experimental techniques now available. Only through modeling can the complex processes be analyzed, and only through theory can the accelerated test procedures be understood well enough to serve as the basis for the extrapolation of modeled behavior over long periods of time.

Atomic-level simulations of radiation effects in metals, intermetallics, and semiconductors is an active area of research. ${ }^{210}$ Quantum mechanical and empirical models of atomic bonding, energy minimization, molecular dynamics (MD), and Monte Carlo (MC) methods can be used in atomic-level calculations of radiation damage processes in crystalline (and amorphous) materials. ${ }^{211}$ Energy minimization is limited to zero Kelvin but is widely used to study structures, stable defect configurations, and energy minima for defect motion. Static defect properties as well as dynamic processes on the order of picoseconds can be modeled by MD simulations. Molecular dynamics can be used to study defect formation and migration energies, damage mechanisms, and defect production processes in cascades. Monte Carlo techniques, which predict behavior from a random sampling of initial states, are useful for calculating damage distributions (e.g., Figs. 4 and 5), thermodynamic equilibrium structures and properties, phase separation, and long-range diffusion.

As noted, atomic-level simulations of radiation effects have focused largely on metals, intermetallics, and semiconductors, and the consistent conclusions from these studies are that a liquid-like core is generated during an intense collision cascade. This subsequently relaxes back to the crystalline structure, but with a larger than equilibrium number of defects, such as vacancies and interstitials. These tend to aggregate, forming vacancy loops and clusters of interstitials. In a study of glassy metals, Mattila et al. ${ }^{212}$ concluded that there is melting around the core of the cascade, as in crystalline metals, but this melted region does not relax back to the original structural state, producing instead a permanent structural change in these glassy metals.

Computer simulations of radiation effects in amorphous silica and complex silicate glasses are generally more complicated because of the presence of more than one atom type, mixied ionic-covalent bonding, complex structures, and stoichiometry effects. Effective interatomic potentials for amorphous silica have been developed and used in MD simulations of displacement cascades $^{213}$ and to calculate the structure, density, heat capacity, and compressibility. ${ }^{214}$ Molecular dynamics is especially useful in modeling glass structures, since it does not require the precise structure to be given as input. MD simulations of the structure of lead silicate ${ }^{215}$ and alkali silicate ${ }^{216}$ glasses have been shown to reproduce experimentally measured bulk structural features, such as interatomic distances and average coordination numbers. With the development of appropriate interatomic potentials, it should be possible to model the atomic structure and simulate both diffusion and radiation effects in more complex silicate glasses. For multicomponent silicate (or phosphate) glasses, the amorphous structure raises several problems. First, it may be necessary to look at a number of different structural arrangements (e.g., presence of more than one type of network ${ }^{215}$ ). Secondly, the amorphous systems have networks that require angledependent forces, so simple potentials will not suffice. This is less of a problem for the network modifiers, which do not form part of the network itself. While MD simulations of complex glasses is in an early stage of development, it has been shown that a number of ion transport properties, such as alkali ion migration energies, can be calculated in multi-component silicate glasses. ${ }^{217,218}$ Such calculations of network modifier motion rationalize the compositional dependence in terms of the structural features of the simulated structures. In addition, it has been shown that MD simulations of multicomponent silicate glasses can be used to calculate a number of measurable structural properties, including density, thermal expansion coefficient, and viscosity. ${ }^{217,218}$

Delaye and Ghaleb $^{219}$ have modeled a simplified (5-component) waste glass using pair potentials modulated by 3-body terms for certain components $\left(\mathrm{SiO}_{2}\right.$, $\mathrm{B}_{2} \mathrm{O}_{3}, \mathrm{Al}_{2} \mathrm{O}_{3}$ ). Simulations of displacement cascade events have been performed in this model waste glass and provide information about ion displacements and consequent structural rearrangement of the glass. ${ }^{220-222}$ Oxygen and sodium were the most frequently displaced atoms in the simulations of cascade events in this simplified waste glass. This observation is consistent with simulations of cascades in amorphous silica, where oxygen atoms are predominately displaced. ${ }^{213}$ These initial computer simulation studies suggest that a cascade in a simplified borosilicate waste glass drives alkali atoms to the edge of the cascade and increases the ratio of trigonally to tetrahedrally bonded boron, thus also creating more nonbridging oxygens and diminishing the network connectivity. The calculations also highlighted the difficulty of defining a displacement when there is 
no reference crystalline lattice. Electronic excitations are not currently taken into account in these simulations.

Changes to the glass structure as a result of cascade events can be quantified from simulations, and such structural changes should be investigated by spectroscopic and diffuse scattering techniques, as well as by changes in physical properties. This is an example of the very desirable interaction of modeling and experiment. Molecular dynamics can be used to estimate directly the observable consequences of radiation damage in glasses. In some cases, other calculations may be needed, and spectroscopic changes would need electronic structure calculations as well. It is therefore important to extend existing simulation work on structure and diffusion in oxide glasses to the area of radiation effects and to expand on the use of MD simulations to study cascades in complex glasses, as in the work of Delaye and Ghaleb. ${ }^{221,222}$

An important issue concerns the complexity of the waste form glass systems. Here one is concerned with two types of structural detail: the large number of different species and the nature of the charge state of the key components. In particular, the actinides can occur in several different charge states, as can the $\mathrm{Fe}$ and $\mathrm{Ti}$, which are invariably found in the waste stream. The charge state issue is just one of the areas in which the behavior of the electron is crucial. A complete understanding of the mechanisms associated with radiation effects must also include an explicit consideration of the behavior of electrons and holes. This means that one must move beyond purely classical techniques. For example, network ions and defect species may change their charge state during the damage processes. Electronic excitation can also lead to damage or different molecular species through chemical processes involving excited electrons, such as in the formation of peroxy radicals or superoxide ions discussed above. It is possible to speculate that in the center of the $\alpha$-recoil cascade excited state dynamics will influence both defect formation and ion transport, while the energy is carried away by both photons and electrons. The electron displacements may be greater than ion movements, and this kind of charge redistribution may lead to the buildup of electric fields at both microscopic and mesoscopic length scales, causing additional separation of charges, either of electron-hole pairs, or of positive and negative ions. The effects of this on the structural rearrangements in a cascade event need to be considered because the motion of charges is heavily influenced by electric fields.

The importance of electronic processes in radiation effects is obvious, but the nature of these processes and their influence over structural changes is far less clear. Given that the spatial extent of the electronic processes may be substantial (electron mean free paths of $1 \mathrm{~nm}$ are not long, but access many sites), and that the host glasses will contain a variety of aliovalent ions (such as transition metals from the waste stream and, of course, the actinides), it is necessary to understand the nature of the charge states of these species, since electron transfer reactions also underlie chemical durability properties. The objective of the theory here is to understand the nature of the charge states and their role in structural stability.

As with any theoretical approach, the issue of "validation" is critical, if the techniques are to be predictive and significantly more than just a rationalization of empirical observations. The use of structure as one test is attractive for a number of reasons. Firstly, given that atomic positions are a natural product of $\mathrm{MD}$, it can be used to predict the macroscopically measurable properties, such as the neutron total correlation function, $T(r)$, which is available from diffraction studies. Similarly, EXAFS spectra may be calculated from the simulations. In fact, the simulations offer a natural link between all the experimental probes of structure. They offer a route to develop a picture of the structure which is consistent with all the available experimental data. Reverse Monte Carlo methods that have been applied to oxide glasses ${ }^{223,224}$ can be used for waste form glasses.

Another approach useful in "validation" is thermodynamic. Many of the quantities of interest are energies, and one must have confidence in the predictions of energies from simulations. These are a by-product of MD simulations, although other methods may be more accurate once the geometry is defined. The energies might be the relative stability of different phases, or whether or not dissolution is exothermic. Some work in this area has been done for crystals, ${ }^{225}$ but not yet for glasses. In addition, defect and ion migration energies are of considerable interest. For example, Cormack and $\mathrm{CaO}^{217}$ have shown that the mixed alkali effect in multicomponent glasses is reproduced by MD simulations, and changes in sodium ion activation energy as a function of $\mathrm{Al}$ content also mirror experimental trends, suggesting that the structural geometry for these glasses is basically correct.

Advancements in the simulation and modeling of radiation effects in complex glasses will require the application of different methodologies. A $b$ initio methods can be used to develop improved interatomic potentials and to investigate the electronic state of small structures. MD simulations with improved potentials can be used to model the radiation damage state and defect energetics; however, it will be important to include new methodolgies, as they are developed, that allow electronic excitiations and changes in charge state. An important goal, however, is the modeling and simulation of the effects of time and temperature on the damage state, defect interactions, diffusion, relative energy state, 
and evolution of microstructure (e.g., bubbles and voids). This will require Monte Carlo methods and theoretical models to investigate the effects of multiple radioactive decay (damage) events and defect diffusion and annealing on damage accumulation and microstructural evolution on longer time scales and macroscopic systems. For example, mathematical rate theory, similar to that used to describe microstructural evolution in crystalline materials, ${ }^{226,227}$ could be applied to the formation of bubbles in complex glasses. In addition, methods need to be developed to incorporate defects detected spectroscopically, incorporate potential gradients (e.g., stress, thermal, electric field), define a displacement, calculate property changes (e.g., stored energy), and allow compaction or expansion of the structure. An important outcome should be the development of predictive models of radiation effects in complex glasses that can be combined with atomistic theories/models of glass dissolution.

\section{RESEARCH FACILITIES}

Research facilities needed in order to investigate the effects of radiation on glasses for HLW or $\mathrm{Pu}$ disposal range include actinide research laboratories, $\gamma$-irradiation facilities, and modern electron- and ionirradiation facilities. For actinide research, the radiation effects accumulate continuously over long times, and in situ measurements under controlled conditions (temperature, thermal gradient, stress, etc.) are possible but perhaps less necessary than for accelerated techniques. In situ measurements are possible in many $\gamma$-irradiation facilities, ion-beam irradiation facilities, and electronbeam or electron microscopy facilities.

Many modern research techniques and facilities are available to the materials science community that provide unique opportunities to systematically investigate radiation effects in nuclear waste glasses. The techniques range from probes of the local atomic environment to bulk characterization and make use of major user facilities with accelerator-based photon sources, neutron scattering facilities, and high-energy or high-resolution electron microscopes. These techniques and facilities need to be made available for the study of radiation effects in radioactive materials, including those containing actinides.

\section{A. Actinide research facilities}

Modern laboratories that perform research on actinide containing materials are very limited. Many laboratories with capabilities to handle radioactive materials, including actinides, have been shutdown on the DOE sites as a result of the transformation from weapons production to environmental remediation. The capabilities to handle and study actinides are decreasing each year. It is therefore disturbing that with the 33 metric tons of plutonium residue and scraps, 50 to 100 metric tons of weapons grade plutonium, and 650 metric tons of plutonium in spent commercial nuclear fuel to be stabilized, stored, and sent to disposal that there are so few laboratories equipped with modern analytical capabilities to handle radioactive materials. Fortunately, many of the advanced characterization techniques (e.g., ESR, neutron scattering, Raman spectroscopy, and NMR) can handle encapsulated materials, but these instruments are often located in laboratories where radioactive materials are no longer allowed. There is, unfortunately, no central multiuser facility for handling radioactive materials, particularly actinides, with all the necessary characterization facilities; consequently, detailed characterization of specimens often requires shipping from site to site and, in some cases, re-encapsulation for each technique.

\section{B. Gamma irradiation facilities}

Several ${ }^{60} \mathrm{Co}$ gamma irradiation facilities exist at DOE sites; these include the Pacific Northwest National Laboratory, Sandia National Laboratories, Argonne National Laboratory, and the Savannah River Site. Several of these sites have been used in instrumented studies of glass corrosion. Studies of the effects of temperature, thermal gradients, stress gradients, and electron fields are feasible. In situ optical and electrical measurements are also feasible. In many of these ${ }^{60} \mathrm{Co}$ facilities the gamma field is nonisotropic. More isotropic gamma fields are possible using spent fuel, particularly the spent, cylindrical fuel at HFIR, which is hollow along the cylindrical axis. Understanding ionization damage in HLW glasses from $\beta$-particles and $\gamma$-rays would benefit immensely from controlled temperature studies and in situ measurements of glass specimens in $\gamma$-facilities.

\section{Ion-beam irradiation facilities}

There are numerous ion-beam irradiation facilities at DOE sites, universities, and industry laboratories. Some include dual and triple beam capabilities that allow simultaneous irradiation with several species, so as to simulate both the alpha particle and the recoil nucleus that are produced during alpha decay. These multibeam facilities also allow in situ ion-beam characterization (Sandia National Laboratories and Los Alamos National Laboratory ${ }^{228}$ ) or electron-beam characterization (IVEM and HVEM facilities at Argonne National Laboratory ${ }^{229}$ ). The ion-beam analysis techniques, which are primarily used to measure changes in near-surface chemical compositions, include Rutherford backscattering (RBS), elastic recoil detection (ERD), nuclear reaction analysis (NRA), and particle-induced $x$-ray emission (PIXE). Light elements that are usually difficult to detect with RBS are easily measured with ERD methods. In addition, microbeam capabilities would allow the analysis 
of phase separated regions. These ion-beam irradiation facilities also could be equipped with in situ optical characterization. A cantilever-beam apparatus ${ }^{89}$ is available (Sandia National Laboratories) for measurements of volume changes induced by ion-beam irradiation. There are also a number of ion-beam irradiation facilities at universities (e.g., University of Michigan, University of Illinois, and Alabama A\&M University).

\section{Electron-beam irradiation facilities}

High-voltage electron microscopes, such as those at Argonne National Laboratory and Lawrence Berkeley National Laboratory, can be used to simulate highenergy beta particle damage. Conventional electron microscopes that operate in the range of 100 to $400 \mathrm{kV}$ can also be used to simulate beta particle damage. Unfortunately, these facilities have extremely high dose rates as compared with the damage rates in glasses containing HLW or actinides, producing in microseconds the equivalent damage of 1000 years storage. Other useful facilities may be the pulsed electron-beam facilities at Argonne National Laboratory and Brookhaven National Laboratory. In situ characterization capabilities include time-resolved EPR and fluorescence, and other capabilities could be added.

\section{RESEARCH NEEDS}

There are many scientific issues to be resolved in order to advance the understanding of radiation effects in complex glasses and to provide for predictive modeling of nuclear waste glass behavior over long periods of time. In this section, recommendations for research priorities are summarized from the previous discussions. The primary objective of these recommendations is to develop fundamental knowledge and models of radiation-glass interactions at the atomic, microscopic, and macroscopic levels in order to provide for the evaluation and performance assessment of glass waste forms used for the immobilization and disposal of highlevel waste and weapons-grade $\mathrm{Pu}$.

\section{A. Reference glass compositions}

Because so many different techniques and disciplines must contribute to progress in this field, it is important that radiation effects studies, as well as other studies (e.g., dissolution and thermal stability), be performed on well-characterized reference glasses. It is recommended that a few specific glass compositions (simple to complex) be prepared, characterized for composition and homogeneity, and made available to the scientific community. As a minimum, a three-tiered approach to glass complexity should be followed: (i) a simple system (an alkali silicate), (ii) a model system of intermediate complexity (a four or five component glass), and (iii) a simulated waste glass (DWPF glass, $\mathrm{Pu}$ glass, or others). Other glass systems that should be studied include: (i) Na-B-silicate, (ii) Na-B-Fe-silicate, (iii) Na-B-(Ln,Ac)-silicate, and (iv) lead-iron phosphate. There should be a major attempt to coordinate and communicate the results of all studies (radiation effects, dissolution, thermal stability) on these glasses among those scientists active in the nuclear waste field. Results should be published in the refereed literature and not in the gray literature of laboratory reports.

\section{B. Structural and thermodynamic properties}

Much of the data on structure, phase equilibria, and thermodynamic parameters for the glass compositions currently under consideration are missing, poorly documented, or not readily accessible as they are found in internal DOE or laboratory reports. Systematic studies of the structure and energetics of stable and metastable phases in these glass systems are an essential step to understanding how the system approaches or deviates from equilibrium under radiation. Such structural and thermodynamic studies must include both model glasses and glasses containing actinides, which may require placing appropriate instrumentation (e.g., calorimeters) in radiation zones or gloveboxes. Structural characterization should include determination of intrinsic defects, short and intermediate range order, and the local environment of important radionuclides. Measurements of heat capacities, glass transition temperatures, enthalpies of rapid relaxation processes, and total stored energy will be required in order to determine the relative energy state of the irradiated glasses.

\section{Systematic irradiation studies}

Systematic studies of irradiation effects in reference glasses and simulated waste glasses, including archived glasses containing $\mathrm{Pu}$ or $\mathrm{Cm}$, must be performed over the widest range of conditions (i.e., dose, dose rate, and temperature). This is required in order to identify the fundamental processes underlying radiation effects in these glasses and to develop a scientific understanding of the balance between radiation damage production, microstructure evolution, and recovery processes as functions of temperature and dose rate. Only from such understanding will it be possible to predict with any degree of certainty the effects of radiation under actual repository or disposition conditions. Simple engineeringtype tests at expected temperatures, as might be proposed for some acceptance criteria, provide limited scientific understanding and unreliable performance predictions when the fundamental damage processes, damage kinetics, and dose-rate effects are unknown. 
The systematic studies must include measurements of the energetics of the radiation damage processes and the relative energy state of the damaged glasses both to understand the effects of radiation on properties and reactivity and to provide a means of validation for computer simulations and model predictions. These systematic studies should focus on the following: (1) understanding the relative effects of ionization and ballistic collision processes on defect generation and radiation effects; (2) resolving the controversy regarding radiolytic (oxygen) bubble formation in HLW glasses; (3) developing an understanding of radiation-induced bubble formation, radiation-induced phase transformation, radiation-enhanced diffusion, and the role of thermal, stress, and electric field gradients on these processes as functions of dose rate and temperature; (4) understanding helium accumulation, trapping, bubble formation, and release in glass compositions for $\mathrm{Pu}$ (or other actinide) disposition; (5) since accelerated irradiation techniques must be employed in these studies of radiation effects, it is imperative that a thorough understanding of doserate effects be developed and that high-dose-rate techniques (e.g., ion and electron irradiations) be validated through comparisons with data on actinide-containing or gamma-irradiated glasses and with theoretical models and computer simulations.

\section{Theory and computer simulations}

Theoretical modeling and computer simulation techniques are needed to provide: (i) atomistic interpretations of experimental results; (ii) relationships between composition, atomic structure, and volume changes; (iii) an understanding of ionization and ballistic-collision processes; (iv) atomistic details of the primary damage state; (v) defect structures and energetics; (vi) an understanding of dose-rate effects and the limitations of accelerated irradiation techniques; (vii) models of defect/gas diffusion and interactions; and (viii) models of microstructure evolution (e.g., bubble formation). In addition, computer simulations should be used to ascertain and interpret the short-range and intermediate-range order in glasses (e.g., local bond coordination and ring-size distribution), calculate spectral features (e.g., x-ray and laser spectroscopies), and predict observable effects of radiation damage in glasses for experimental confirmation. Advancements in this area will require the use of different methodologies: $a b$ initio methods to develop improved interatomic potentials and investigate the electronic state of small structures; molecular dynamic simulations with improved potentials to model the radiation damage state; and Monte Carlo methods and theoretical models to investigate the effects of multiple radioactive decay (damage) events and defect diffusion on damage accumulation and microstructure evolution on longer time scales and macroscopic systems.
Electronic excitation processes are important in the development of radiation effects in these complex glasses. Classical methodologies do not account for the electronic processes; consequently, new methodologies need to be developed that allow the transfer of energy to electronic excitations, the ability of ions to change charge states, and the formation of excitons, peroxy radicals, and molecular species (e.g., oxygen). In addition, methods to incorporate defects detected spectroscopically, incorporate potential gradients (e.g., stress, thermal, electric field), define a displacement, calculate property changes (e.g., stored energy), and allow compaction or expansion of the structure need to be developed. In all cases, validation of the models and simulation methods is critical. Finally, predictive models of long-term nuclear waste glass performance will require combining atomistic and macroscopic models of radiation effects in complex glasses with atomistic theories and models of glass dissolution.

\section{E. Facilities}

Existing facilities for radiological work need to be maintained and a central multiuser facility to handle and characterize radioactive materials is needed. The various irradiation facilities (electrons, ions, $\mathrm{x}$-rays, and $\gamma$-rays) currently available are adequate, but resources to perform in situ and controlled environment (e.g., temperature) studies need to be available.

\section{F. Attract talented scientists}

The panel expressed concern that this field does not attract graduate students, and much of the relevant knowledge and experiences will disappear with the passage of time. With the complex needs for remediation at the DOE sites, and the need for disposition of weapons $\mathrm{Pu}$, there is a need for a relatively small but stable pool of expertise and facilities. It is imperative to attract and involve bright new minds with new ideas to this field. Increased opportunities need to be made available to support graduate students and provide post doctoral experience at universities, the national laboratories, and other DOE sites. A long-term research program, with a continuity of purpose, is essential to attracting and retaining high caliber scientists.

\section{ACKNOWLEDGMENTS}

This panel was sponsored by the Council on Materials Science of the United States Department of Energy, Office of Basic Energy Sciences, Division of Materials Sciences (DMS/BES) under Contract DEFG02-96ER45439 at the University of Illinois. The Panel would like to thank Dr. Iran Thomas, DMS/BES Director, and Dr. Robert Gottschall, Metallurgy and Ceramics Branch Chief, for their support. They also gratefully 
acknowledge the support and encouragement of Professor C. Peter Flynn (University of Illinois-Urbana), Chairman of the Council on Materials Science, whom provided liaison with DMS/BES and actively participated in the Panel Meeting in Santa Fe. The Panel thanks Professor David Clarke (University of CaliforniaSanta Barbara) and Dr. Michael Knotek (Pacific Northwest National Laboratory), members of the Council on Materials Science, and Dr. Yok Chen (DOE, DMS/BES) for their active participation in the Panel Meeting. The Panel also gratefully acknowledges Dr. John Bates (Argonne National Laboratory) and Dr. Ned Bibler (Savannah River Technology Center) for the background tutorials presented to the panel.

\section{REFERENCES}

1. Closing the Circle on the Splitting of the Atom (U.S. Department of Energy, Office of Environmental Management, Washington, DC, 1995).

2. Management and Disposition of Excess Weapons Plutonium (National Academy Press, Washington, DC, 1994).

3. Management and Disposition of Excess Weapons PlutoniumReactor-Related Options (National Academy Press, Washington, DC, 1995)

4. G. G. Wicks, A. R. Lodding, and M. A. Molecke, MRS Bull. XVIII (9), 33 (1993).

5. C. M. Jantzen, J. Am. Ceram. Soc. 75 (9), 2433 (1992).

6. B. Grambow, MRS Bull. XIX (12), 20 (1994).

7. Storage and Disposition of Weapons-Usable Fissile Materials Draft Programmatic Environmental Impact Statement, DOE/EIS0229-D (U.S. Department of Energy, Washington, DC, 1996).

8. Defense Waste Processing Facility - Cost, Schedule, and Technical Issues, GAO/RCED 92-183 (U.S. General Accounting Office, Washington, DC, 1992).

9. W. Lutze, presented at the National Research Council Workshop on Glass as a Waste Form and Vitrification Technology, Washington, DC, May 13-15, 1996 (unpublished).

10. Cunnane and J. M. Allison, in Scientific Basis for Nuclear Waste Management XVII, edited by A. Barkatt and R. A. Van Konynenburg (Mater. Res. Soc. Symp. Proc. 333, Pittsburgh, PA, 1994), p. 3.

11. Waste Form Compliance Plan for the West Valley Demonstration Project High-Level Waste Form, WVDP-185 (West Valley Demonstration Project, West Valley, NY, 1995).

12. D. B. Amerine, presented at the National Research Council Workshop on Glass as a Waste Form and Vitrification Technology, Washington, DC, May 13-15, 1996 (unpublished).

13. D. L. Illman, Chemical \& Engineering News 71 (25), 9 (1993).

14. Office of Technology Assessment, Complex Cleanup: The Environmental Legacy of Nuclear Weapons Production, OTA-O-484 (Congress of the United States, Washington, DC, 1991).

15. Disposal of Weapon Plutonium, edited by E. R. Merz and C.E. Walter (Kluwer Academic Publishers, The Netherlands, 1996).

16. A. Makhijani and A. Makhijani, Fissile Materials in a Glass, Darkly (IEER Press, Takoma Park, MD, 1995).

17. E. Browne, J. M. Dairiki, and R. E. Doebler, Table of Isotopes, edited by C. M. Lederer and V.S. Sherley, 7th ed. (John Wiley and Sons, New York, 1978).

18. G. Taubes, Science 268, 1836 (1995).

19. C. D. Bowman and F. Venneri, Sci. Glob. Secur. 5, 279 (1996).

20. R. A. Van Konynenburg, Sci. Glob. Secur. 5, 303 (1996).
21. N.E. Bibler, W. G. Ramsey, T.F. Meaker, and J.M. Pareizs, in Scientific Basis for Nuclear Waste Management XIX, edited by W. M. Murphy and D. A. Knecht (Mater. Res. Soc. Symp. Proc. 412, Pittsburgh, PA, 1996), p. 65.

22. J. K. Bates, A.J.G. Ellison, J.W. Emery, and J.C. Hoh, in Scientific Basis for Nuclear Waste Management XIX, edited by W. M. Murphy and D. A. Knecht (Mater. Res. Soc. Symp. Proc. 412, Pittsburgh, PA, 1996), p. 57.

23. Hj. Matzke, Special issue for a workshop on Radiation Damage Effects in Nuclear Waste Materials, Nucl. Instrum. Methods in Phys. Res. B 32, 453 (1988).

24. W. J. Weber, L. K. Mansur, F. W. Clinard, Jr., and D. M. Parkin, J. Nucl. Mater. 184, 1 (1991).

25. W. J. Weber and F. P. Roberts, Nucl. Technol. 60, 178 (1983).

26. W. G. Burns, A.E. Hughes, J. A.C. Marples, R. S. Nelson, and A. M. Stoneham, J. Nucl. Mater. 107, 245 (1982).

27. W. G. Burns, A.E. Hughes, J. A.C. Marples, R. S. Nelson, and A. M. Stoneham, in Scientific Basis for Nuclear Waste Management $V$, edited by W. Lutze (Mater. Res. Soc. Symp. Proc. 11, Pittsburgh, PA, 1982), p. 339.

28. D. H. Day, A.E. Hughes, J. W. Leake, J.A.C. Marples, G.P. Marsh, J. Rae, and B. O. Wade, Rep. Prog. Phys. 48, 101 (1985).

29. W. J. Weber, Nucl. Instrum. Methods in Phys. Res. B 32, 471 (1988).

30. W. J. Weber, J. Minerals, Metals and Materials Sociery 43 (7), 35 (1991).

31. D. J. Wronkiewicz, Effects of Radionuclide Decay on Waste Glass Behavior-A Critical Review, ANL-93/45 (Argonne National Laboratory, Argonne, IL, 1993).

32. R. C. Ewing, W. J. Weber, and F.W. Clinard, Jr., Progress in Nuclear Energy 29 (2), 63 (1995).

33. W. J. Weber and R.C. Ewing, in Scientific Basis for Nuclear Waste Management XVIII, edited by T. Murakami and R. C. Ewing (Mater. Res. Soc. Symp. Proc. 353, Pittsburgh, PA, 1995), p. 1389.

34. W. J. Weber, R. C. Ewing, and W. Lutze, in Scientific Basis for Nuclear Waste Management XIX, edited by W. M. Murphy and D. A. Knecht (Mater. Res. Soc. Symp. Proc. 412, Pittsburgh, PA, 1996), p. 25.

35. Radioactive Waste Forms for the Future, edited by W. Lutze and R. C. Ewing (North-Holland, Amsterdam, 1988).

36. R. C. Ewing, J. Nucl. Mater. 190, vii (1992).

37. T. A. Buscheck, J. J. Nitao, and L. D. Ramspott, in Scientific Basis for Nuclear Waste Management XIX, edited by W. M. Murphy and D. A. Knecht (Mater. Res. Soc. Symp. Proc. 412, Pittsburgh, PA, 1996), p. 715.

38. J.F. Ziegler, J.P. Biersack, and U. Littmark, The Stopping and Range of Ions in Solids (Pergamon, New York, 1985).

39. W. J. Gray, Nature (London) 296, 547 (1982).

40. R.P. Turcotte, Radiation Effects in Solidified High-Level Wastes-Part 2, Helium Behavior, BNWL-2051 (Pacific Northwest National Laboratory, Richland, WA, 1976).

41. S. Sato, H. Furuya, K. Morikawa, M. Sugisaki, and Y. Inagaki, J. Nucl. Sci. and Technol. 27, 343 (1990).

42. B. J. Todd, J. L. Lineweaver, and J. T. Kerr, J. Appl. Phys. 31, 51 (1960).

43. J. L. Lineweaver, J. Appl. Phys. 34, 1786 (1963).

44. N.E. Bibler, in Scientific Basis for Nuclear Waste Management, edited by S. V. Topp (Mater. Res. Soc. Symp. Proc. 6, NorthHolland, New York, 1982), p. 681.

45. Standard Method for Testing the Long Term Alpha Irradiation Stability of Solidified High-Level Radioactive Waste Forms, ISO 6962 (International Organization for Standardization, Geneva, Switzerland, 1982).

46. Nuclear Waste Materials Handbook, Test Methods, DOE/TIC11400 (Pacific Northwest Laboratory, Richland, WA, 1981). 
47. W. J. Weber, J. W. Wald, and G. L. McVay, J. Am. Ceram. Soc. 68 (9), C-253 (1985).

48. G. Wagner and P. van den Haute, Fission-Track Dating (Kluwer Academic Publishers, Dordrecht, The Netherlands, 1992).

49. Y. Eyal and R. C. Ewing, in Proceedings of the International Conference on Nuclear Waste Management and Environmental Remediation, Vol. 1, edited by D. Alexandre, R. Baker, R. Kohout, and J. Marek (ASME Press, New York, 1993), p. 191.

50. R. L. Fleischer, Science, 207, 979 (1980).

51. G. W. Arnold, C. J. M. Northrup, and N.E. Bibler, in Scientific Basis for Nuclear Waste Management-V, edited by W. Lutze (Mater. Res. Soc. Symp. Proc. 11, Pittsburgh, PA, 1982), p. 357.

52. G. Malow and H. Andresen, in Scientific Basis for Nuclear Waste Management, Vol. 1, edited by G.J. McCarthy (Plenum Press, New York, 1979), p.109.

53. M. Antonini, F. Lanza, and A. Manara, in Ceramics in Nuclear Waste Management, edited by T.D. Chikalla and J.E. Mendel, CONF-790420 (National Technical Information Service, Springfield, VA, 1979), p. 289.

54. L. F. Curtiss, Nature (London) 120, 406 (1927).

55. S. C. Lind, Science 68, 643 (1928).

56. D. G. Tuck, Int. J. Appl. Radiat. Isotopes 15, 49 (1964).

57. E. Lell, N. J. Kreidl, and J.R. Hensler, in Progress in Ceramic Science, Vol. 4, edited by J. Burke (Pergamon Press, Oxford, New York, 1966), p. 1.

58. D. L. Griscom, in Glass: Science and Technology Vol. 4B, edited by D. R. Uhlmann and N. J. Kreidl (Academic Press, Boston, 1990), p. 151.

59. F. W. Clinard, Jr. and L. W. Hobbs, in Physics of Radiation Effects in Crystals, edited by R. A. Johnson and A. N. Orlov (Elsevier, Amsterdam, 1986), p. 387.

60. R. A. B. Devine, Nucl. Instrum. Methods in Phys. Res. B 91, 378 (1994).

61. F. Farges, R.C. Ewing, and G. E. Brown, Jr., J. Mater. Res. 8, 1983 (1993).

62. L. W. Hobbs, J. Non-Cryst. Solids 192 \& 193, 79 (1995).

63. A.C. Wright, B. Bachra, T.M. Brunier, R. N. Sinclair, L.F. Gladden, and R. L. Portsmouth, J. Non-Cryst. Solids 150, 69 (1992).

64. L. W. Hobbs, Nucl. Instrum. Methods in Phys. Res. B 91, 30-42 (1994).

65. C. S. Marians and L. W. Hobbs, J. Non-Cryst. Solids 119, 269 (1990).

66. L. F. Gladden, J. Non-Cryst. Solids 119, 318 (1990).

67. P. Vashishta, A. Nakano, R. K. Kalia, and I. Ebbsjo, J. Non-Cryst. Solids 182, 59 (1995).

68. A. G. Revesz and G. V. Gibbs, in The Physics of MOS Insulators, edited by G. Lucovsky, S.T. Pantelides, and F.L. Galeener (Pergamon, New York, 1980), p. 92.

69. C.S. Marians and J.K. Burdett, J. Non-Cryst. Solids 124, 1 (1990).

70. E. J. Friebele, D. L. Griscom, M. Stapelbroek, and R. A. Weeks, Phys. Rev. Lett. 42, 1346 (1979).

71. L. W. Hobbs and M. R. Pascucci, J. Phys. 41 (C6), 237 (1980).

72. F. Wooten and D. Weaire, J. Non-Cryst. Solids 64, 325 (1984).

73. U. Jain, A.C. Powell, and L.W. Hobbs, in Defects in Materials, edited by P.D. Bristowe, J.E. Epperson, J.E. Griffith, and Z. Lillental-Weber (Mater. Res. Soc. Symp. Proc. 209, Pittsburgh, PA, 1991), p. 201.

74. D. J. Jacobs and M.F. Thorpe, Phys. Rev. E 52, 3682 (1996).

75. P. K. Gupta, J. Am. Ceram. Soc. 76, 1088 (1993).

76. G. N. Greaves, J. Non-Cryst. Solids 71, 203 (1985).

77. B. C. Sales, J. O. Ramey, J.C. McCallum, and L. A. Boatner, J. Non-Cryst. Solids 126, 179 (1990).

78. W. Primak, L. H. Fuchs, and P. Day, Phys. Rev. 92, 1064 (1953).
79. W. Primak, Phys. Rev. 110, 1240 (1958).

80. M. Whittels and F. A. Sherrill, Phys. Rev. 93, 1117 (1954).

81. E. P. EerNisse, J. Appl. Phys. 45, 167 (1974).

82. H. M. Presby and W. L. Brown, Appl. Phys. Lett. 24, 511 (1974).

83. G. W. Arnold, Radiat. Eff. 65, 17 (1982).

84. S. Sato, H. Furuya, Y. Inagaki, T. Kozaka, and M. Sugisaki, J. Nucl. Sci. Technol. 24, 920 (1987).

85. S. Sato, H. Furuya, K. Asakura, K. Ohta, and T. Tamai, Nucl. Instrum. Methods in Phys. Res. B 1, 534 (1984).

86. J. E. Shelby, J. Appl. Phys. 51, 2561 (1980).

87. W. Primak and R. Kampwirth, J. Appl. Phys. 39, 6010 (1968).

88. C. B. Norris and E. P. EerNisse, J. Appl. Phys. 45, 3876 (1974).

89. G. W. Arnold, in Scientific Basis for Nuclear Waste Management VIII, edited by C. M. Jantzen, J. A. Stone, and R. C. Ewing (Mater. Res. Soc. Symp. Proc. 44, Pittsburgh, PA, 1985), p. 617.

90. A. Hiraiwa, H. Usui, and K. Yagi, Appl. Phys. Lett. 54, 1106 (1989).

91. M. Antonini, A. Manara, and S. Buckley, Radiat. Eff. 65, 55 (1982).

92. M. Antonini, A. Manara, and P. Lensi, in Physics of $\mathrm{SiO}_{2}$ and its Interfaces, edited by S. T. Pantiledes (Pergamon, New York, 1978), p. 316.

93. R. A. B. Devine and M. Marchand, Appl. Phys. Lett. 63, 619 (1993).

94. K. Fukumi, A. Chayahara, M. Satou, M. Hayakawa, M. Hangyo, and S. Nakashima, Jpn. J. Appl. Phys. 29, 905 (1990).

95. A. C. Wright, J. Non-Cryst. Solids 179, 84 (1994).

96. R. A. Weeks, J. Appl. Phys. 27, 1376 (1956).

97. R. A. Weeks, Phys. Rev. 130, 570 (1963).

98. D. L. Griscom, Nucl. Instrum. Methods in Phys. Res. B 1, 481 (1984).

99. F. J. Feigl, W. B. Fowler, and K. L. Yip, Solid State Commun. 14, 225 (1974).

100. K. W. Yip and W. B. Fowler, Phys. Rev. B 11, 2327 (1975).

101. K. C. Snyder and W. B. Fowler, Phys. Rev. B 48, 13238 (1993).

102. R. A. Weeks, Proc. VII Intl. Cong. on Glass, Brussels, Paper No. 41 (1965)

103. R. Tohmon, H. Mizuno, Y. Ohki, K. Sasagane, K. Nagasawa, and Y. Hama, Phys. Rev. B 39, 1337 (1989).

104. H. Imai, K. Arai, H. Hosono, Y. Abe, T. Arai, and H. Imagawa, Phys. Rev. B 44, 4812 (1991).

105. D. L. Griscom, J. Ceram. Soc. Jpn. 99, 923 (1991).

106. A. V. Amossov and A. O. Rybaltovsky, J. Non-Cryst. Solids 75 (1994).

107. D. L. Griscom, in Proc. Thirty-Third Frequency Control Symposium (Electronics Industries Assn., Washington, DC, 1979), p. 109.

108. W. Hayes, M. J. Kane, O. Salimen, R. L. Wood, and S. P. Doherty, J. Phys. C: Solid State 17, 2943 (1984).

109. T.E. Tsai and D.L. Griscom, Phys. Rev. Lett. 67, 2517 (1991).

110. N. Itoh, T. Shimizu-Iyayama, and T. Fujita, J. Non-Cryst. Solids 179, 194 (1994).

111. A. H. Edwards and W. B. Fowler, Phys. Rev. B 26, 6649 (1982).

112. R. L. Pfeffer, in The Physics and Technology of Amorphous $\mathrm{SiO}_{2}$, edited by R. A. B. Devine (Plenum Publishing, New York, 1988), p. 181.

113. R. L. Pfeffer, in The Physics and Chemistry of $\mathrm{SiO}_{2}$ and the Si$\mathrm{SiO}_{2}$ Interface, edited by C. R. Helms and B.E. Deal (Plenum Press, New York, 1988), p. 169.

114. E. J. Friebele, D. L. Griscom, M. Stapelbroek, and R. A. Weeks, Phys. Rev. Lett. 42, 1346 (1979).

115. M. Stapelbroek, D. L. Griscom, E. J. Friebele, and G. H. Sigel, Jr., J. Non-Cryst. Solids 32, 313 (1979).

116. D. L. Griscom, J. Non-Cryst. Solids 68, 301 (1984). 
117. D. L. Griscom, G.H. Sigel, Jr., and R. J. Ginther, J. Appl. Phys. 47, 960 (1976).

118. E. J. Friebele and D. L. Griscom, in Defects in Glasses, edited by F. L. Galeener, D. L. Griscom, and M. J. Weber (Mater. Res. Soc. Symp. Proc. 61, Pittsburgh, PA, 1986), p. 319.

119. D. L. Griscom, E. J. Friebele, K. J. Long, and J.W. Fleming, J. Appl. Phys. 54, 3743 (1983).

120. G. W. Arnold, Radiat. Eff. 98, 55 (1986).

121. G. W. Arnold, Nucl. Instrum. Methods in Phys. Res. B 1, 516 (1984).

122. G. Battaglin, G. Della Mea, G. De Marchi, P. Mazzoldi, and O. Puglisi, J. Non-Cryst. Solids 50, 119 (1982).

123. G. Battaglin, G. Della Mea, G. De Marchi, P. Mazzoldi, and O. Puglisi, Radiat. Eff. 64, 99 (1982).

124. J. F. DeNatale, D. G. Howitt, and G. W. Arnold, Radiat. Eff. 98, 63 (1986).

125. J. W. H. Schreurs, J. Chem. Phys. 47, 818 (1967).

126. D. L. Griscom, J. Non-Cryst. Solids 64, 229 (1984).

127. R. Cases and D. L. Griscom, Nucl. Instrum. Methods in Phys. Res. B 1, 503 (1984).

128. R. Cases and D. L. Griscom, in Proc. XVI Int'l Cong. Glass, Vol. 3, Glass Structure (1992), p. 53.

129. D. L. Griscom, J. Non-Cryst. Solids 6, 275 (1971).

130. P. W. Levy, J. M. Loman, and J. A. Kierstead, Nucl. Instrum. Methods in Phys. Res. B 1, 549 (1984).

131. N-G. Vannerberg, in Progress in Inorganic Chemistry 4 (1962), p. 125.

132. J. F. DeNatale and D. G. Howitt, Am. Ceram. Soc. Bull. 61, 582 (1982).

133. J. F. DeNatale and D. G. Howitt, Nucl. Instrum. Methods in Phys. Res. B 1, 489 (1984).

134. J.P. Heuer, H.W. Chan, D. G. Howitt, and J.F. DeNatale, in Nuclear Waste Management II, edited by D. E. Clark, W. B. White, and J. J. Machiels (Advances in Ceramics 20, The American Ceramic Society, Westerville, OH, 1986), p. 175.

135. A. Manara, M. Antonini, P. Camagni, and P. N. Gibson, Nucl. Instrum. Methods in Phys. Res. B 1, 475 (1984).

136. P. B. Adams and D. L. Evans, Mater. Res. Sci. 12, 525 (1978).

137. E. Snoeks, T. Weber, A. Cacciato, and A. Polman, unpublished.

138. E. Snoeks, Ph.D. Thesis, Utrecht University (1995).

139. G. W. Arnold, Nucl. Instrum. Methods in Phys. Res. B 32, 504 (1988).

140. S. Klaumünzer, Radiat. Eff. 110, 78 (1989).

141. A. Benyagoub, S. Löffler, M. Rammansee, and S. Klaumünzer, Nucl. Instrum. Methods in Phys. Res. B 65, 228 (1992).

142. D. L. Griscom, in Experimental Techniques of Glass Science, edited by O. El-Bayoumi and C.J. Simmons (The American Ceramic Society, Westerville, OH, 1993), p. 161.

143. D. L. Griscom, J. Chem. Phys. 55, 1113 (1971).

144. J. A. C. Marples, Nucl. Instrum. Methods in Phys. Res. B 32, 480 (1988).

145. Y. Inagaki, H. Furuya, K. Idemitsu, T. Banba, S. Matsumoto, and S. Muraoka, in Scientific Basis for Nuclear Waste Management $X V$, edited by C. G. Sombret (Mater. Res. Soc. Symp. Proc. 257, Pittsburgh, PA, 1992), p. 199.

146. T. Banba, S. Matsumoto, S. Muraoka, K. Yamada, M. Saito, H. Ishikawa, and N. Sasaki, in Scientific Basis for Nuclear Waste Management XVIII, edited by T. Murakami and R.C. Ewing (Mater. Res. Soc. Symp. Proc. 353, Pittsburgh, PA, 1995), p. 1397.

147. M. Antonini, P. Camagni, F. Lanza, and A. Manara, in Scientific Basis for Nuclear Waste Management-2, edited by C.J.M. Northrup, Jr. (Plenum Press, New York, 1980), p. 127.

148. S. Sato, H. Furuya, T. Kozaka, Y. Inagaki, and T. Tamai, J. Nucl. Mater. 152, 265 (1988).
149. A. Manara, P. N. Gibson, and M. Antonini, in Scientific Basis for Nuclear Waste Management-V, edited by W. Lutze (Mater. Res. Soc. Symp. Proc. 11, North-Holland, New York, 1982), p. 349.

150. A. M. Stoneham, Nucl. Instrum. Methods in Phys. Res. B 91, 1 (1994).

151. F. P. Roberts, G. H. Jenks, and C.D. Bopp, Radiation Effects in Solidified High-Level Wastes - Part 1, Stored Energy, BNWL-1944 (Pacific Northwest National Laboratory, Richland, WA, 1976).

152. A. R. Hall, J. T. Dalton, B. Hudson, and J.A.C. Marples, in Management of Radioactive Wastes from the Nuclear Fuel Cycle, Vol. II, IAEA-SM-207 (International Atomic Energy Agency, Vienna, 1976), p. 3.

153. G. Malow, J. A. C. Marples, and C. Sombret, in Radioactive Waste Management and Disposal, edited by R. Simon and S. Orlowski (Harwood Academic Publishers, Chur, Switzerland, 1980), p. 341.

154. A.K. Dé, B. Luckscheiter, W. Lutze, G. Malow, and E. Schiewer, Am. Ceram. Soc. Bull. 55, 500 (1976).

155. J. F. DeNatale and D. G. Howitt, Radiat. Eff. 91, 89 (1985).

156. W. J. Weber, R. P. Turcotte, L.R. Bunnell, F.P. Roberts, and J. H. Westsik, in Ceramics in Nuclear Waste Management, edited by T.D. Chikalla and J.E. Mendel, CONF-790420 (National Technical Information Service, Springfield, VA, 1979), p. 294.

157. S. Sato, K. Asakura, and H. Furuya, Nucl. Chem. Waste Management 4, 147 (1983).

158. J.F. DeNatale and D. G. Howitt, Am. Ceram. Soc. Bull. 66, 1393 (1987).

159. J. P. Heuer, M. S. Thesis, Department of Mechanical Engineering, University of California-Davis 1987.

160. D. G. Howitt, H. W. Chan, J. F. DeNatale, and J. P. Heuer, J. Am. Ceram. Soc. 74, 1145 (1991).

161. M. H. Tosten, TEM examination of irradiated waste glass, WSRCRP 89-584 (Westinghouse Savannah River Co., Aiken, SC, 1989).

162. N. E. Bibler, M. H. Tosten, and D. C. Beam, in High-Level Radioactive Waste Management, Vol. 2 (American Nuclear Society, La Grange Park, IL, 1990), p. 1103.

163. J. Y. Laval and K. H. Westmacott, in Electron Microscopy and Analysis, 1979, edited by T. Mulvey, Conference Series, No. 52 (Institute of Physics, London, 1980), p. 295.

164. Y. Inagaki, H. Furuya, Y. Ono, K. Idemitsu, T. Banba, S. Matsumoto, and S. Muraoka, in Scientific Basis for Nuclear Waste Management XVI, edited by C.G. Interrante and R.T. Pabalan (Mater. Res. Soc. Symp. Proc. 294, Pittsburgh, PA, 1993), p. 191.

165. Hj. Matzke and E. Toscano, Europ. Appl. Res. Rep. 7 (9), 1403 (1990).

166. Hj. Matzke and E. Vernaz, J. Nucl. Mater. 201, 295 (1993).

167. Hj. Matzke and J. van Geel, in Disposal of Weapons Plutonium, edited by E. R. Merz and C. E. Walter (Kluwer Academic Publishers, The Netherlands, 1996), p. 93.

168. R. A. Bonniaud, N. R. Jacquet Francillon, R. L. Laude, and C. G. Sombret, in Ceramics in Nuclear Waste Management, edited by T.D. Chikalla and J.E. Mendel, CONF-790420 (National Technical Information Service, Springfield, VA, 1979), p. 57.

169. J. L. Routbort and Hj. Matzke, Mater. Sci. and Eng. 58, 229 (1983).

170. W. J. Weber and Hj. Matzke, Europ. Appl. Res. Rep. 7 (7), 1221 (1987).

171. M. Yamashita and $\mathrm{Hj}$. Matzke, in Modifications Induced by Irradiation in Glasses, edited by P. Mazzoldi (Elsevier Science, Amsterdam, 1992), p. 53.

172. I. L.F. Ray and Hj. Matzke, unpublished results.

173. R. P. Turcotte, Radioactive Waste Management 2, 169 (1981).

174. J. C. Dran, Y. Langevin, M. Maurette, J. C. Petit, and B. Vassent, in Scientific Basis for Nuclear Waste Management, edited by S. V. 
Topp (Mater. Res. Soc. Symp. Proc. 6, North-Holland, New York, 1982), p. 651.

175. W. Primak, Nucl. Sci. Engr. 80, 689 (1982).

176. D. R. Cousens and S. Myhra, J. Non-Cryst. Solids 54, 345 (1983).

177. J. R. Grover and B.E. Chidley, Reactor Science and Technology (J. Nucl. Energy Parts A/B) 16, 405 (1962).

178. J.R. Grover, in Management of Radioactive Wastes from Fuel Reprocessing (Organisation for Economic Co-Operation and Development, Paris, 1973), p. 593.

179. J. H. Westsik and C. O. Harvey, High-Temperature Leaching of a Simulated High-Level Waste Glass, PNL-3172 (Pacific Northwest Laboratory, Richland, WA, 1981).

180. Y. Eyal and R. L. Fleischer, Geochimica et Cosmochimica Acta 49, 1155 (1985).

181. D. R. Olander and Y. Eyal, Geochimica et Cosmochimca Acta 54, 1889 (1990).

182. A. J. G. Ellison and A. Navrotsky, J. Am. Ceram. Soc. 75, 1430 (1992).

183. A. J. G. Ellison and P.C. Hess, J. Non-Cryst. Solids 127, 247 (1991).

184. R. Calemezuk and E. Bonjour, J. Non-Cryst. Solids 43, 427 (1981).

185. A. Navrotsky, Transaction ACA 27, 1 (1991).

186. S. Susman, K. J. Volin, R. C. Liebermann, G. Gwanmesia, and Y. Wang, Phys. Chem. Glasses 31, 144 (1990).

187. R. J. Hemley, K. K. Mao, P. M. Bell, and B. O. Mysen, Phys. Rev. Lett. 57, 747 (1986)

188. R. H. Stolen, J. T. Krause, and C. R. Kurkijan, Discuss. Faraday Soc. 50, 103 (1970).

189. D. L. Griscom, SPIE 541, 38 (1985).

190. G. W. Arnold and W. D. Compton, Phys. Rev. 116, 802 (1959).

191. R. L. Pfeffer, J. Appl. Phys. 57, 5176 (1985).

192. G. W. Arnold and P. Mazzoldi, in Ion Beam Modification of Insulators, edited by P. Mazzoldi and G. W. Arnold (Elsevier, Amsterdam, 1987), Chap. 5.

193. P. Mazzoldi and A. Miotello, Radiat. Eff. 98, 205 (1986).

194. A. Miotello and P. Mazzoldi, J. Phys. C: Solid State Phys. 15, 5615 (1982)

195. A. Miotello, Phys. Lett. 103A, 279 (1984).

196. W. J. Weber, R. C. Ewing, and L. M. Wang, J. Mater. Res. 9, 688 (1994).

197. P. F. James, J. Mater. Sci. 10, 1802 (1975).

198. Phase Separation in Glass, edited by O. V. Mazurin and E. A. PoraiKoshits (North-Holland, Amsterdam, 1984).

199. P. Taylor, Atomic Energy of Canada Limited Report, AECL10173, August, 1980.

200. W. Haller, D. H. Blackburn, F.E. Wagstaff, and R. J. Charles, J. Am. Ceram. Soc. 53, 34 (1970).

201. R. F. Fudali, M.D. Dayar, D. L. Griscom, and H. D. Schreiber, Geochim. Cosmochim. Acta 51, 2749 (1987).

202. Y-M. Chiang and W.D. Kingery, J. Am. Ceram. Soc. 66, C171 (1983).

203. A. N. Sreeram and L.W. Hobbs, in Beam-Solid Interactions: Fundamentals and Applications, edited by M. Nastasi,
L. R. Harriott, N. Herbots, and R. S. Averback (Mater. Res. Soc. Symp. Proc. 279, Pittsburgh, PA, 1993), p. 559; A. N. Sreeram, Sc.D. Thesis, MIT (1995).

204. D. B. Spilman, L. L. Hench, and D.E. Clark, Nucl. Chem. Waste Management 6, 107 (1986)

205. L. W. Hobbs, F. W. Clinard, Jr., S. J. Zinkle, and R. C. Ewing, J. Nucl. Mater. 216, 291 (1994).

206. J. Yu, W.F. Sommer, and J. N. Bradbury, J. Nucl. Mater. 141-143, 65 (1986); J. Yu, W.F. Sommer, J. N. Bradbury, W. V. Green, and M. Victoria, J. Nucl. Mater. 227, 266 (1996).

207. L. W. Hobbs, in Quantitative Electron Microscopy, edited by J. N. Chapman and A. J. Craven (Scottish Universities Summer Schools in Physics Publ., Edinburgh, 1984), p. 399; Scanning Microscopy, Suppl. 4, 171 (1990)

208. C. R. A. Catlow, K. M. Diller, and L. W. Hobbs, Philos. Mag. 42, 123 (1980).

209. L. W. Hobbs, J. Phys. 37 (C7), 3 (1976).

210. Computer Simulation of Radiation Effects in Solids, edited by T. Diaz de la Rubia, G.H. Gilmer, and M-J. Caturla (North Holland, Amsterdam, 1995).

211. J. B. Adams, A. Rockett, J. Kieffer, W. Xu, M. Nomura, K. A. Kiliam, D. F. Richards, and R. Ramprasad, J. Nucl. Mater. 216, 265 (1994).

212. T. Mattila, R. M. Nieminen, and M. Dzugutov, Nucl. Instrum. Methods in Phys. Res. B 102, 119 (1995).

213. N. V. Doan, Philos. Mag. A49, 683 (1984).

214. R. G. Della Valle and H. C. Andersen, J. Chem. Phys. 97, 2682 (1992).

215. G. Cormier, T. Peres, and J. A. Capobianco, J. Non-Cryst. Solids 195, 125, (1996).

216. B. Vessal, A.C. Wright, and A. C. Hannon, J. Non-Cryst. Solids 196, 233 (1996).

217. A. N. Cormack and Y. Cao, Mol. Eng. (1996), in press.

218. J. M. Delaye and D. Ghaleb, J. Non-Cryst. Solids 195, 239 (1996).

219. J. M. Delaye and D. Ghaleb, Mater. Sci. Eng. B37, 232 (1996).

220. J. M. Delaye, presented at this panel meeting (unpublished).

221. J. M. Delaye and D. Ghaleb, J. Nucl. Mater. (in press).

222. J. M. Delaye and D. Ghaleb, in Proc. of the Third International Conference on Computer Simulations of Radiation Effects in Solids, University of Surrey, Guildford, UK, July 22-26, 1996.

223. J. D. Wicks and R. L McGreevy, J. Non-Cryst. Solids 192/193, 23 (1995).

224. J. D. Wicks, L. Börjesson, G. Bushnell-Wye, W. S. Howells, and R. L. McGreevy, Phys. Rev. Lett. 74, 726 (1995).

225. J-G. Park and A. N. Cormack, Philos. Mag. B 73, 21 (1996).

226. A. D. Brailsford and R. Bullough, J. Nucl. Mater. 44, 121 (1972).

227. U. Jain and A. B. Lidiard, Philos. Mag. 35, 245 (1977).

228. N. Yu, M. Nastasi, T.E. Levine, J.R. Tesmer, M. G. Hollander, C. R. Evans, and C. J. Maggiore, Nucl. Instrum. Methods in Phys. Res. B 99, 566 (1995).

229. C. W. Allen, L. L. Funk, E. A. Ryan, and A. Taylor, Nucl. Instrum. Methods in Phys. Res. B 40/41, 553 (1989). 